\title{
DISRUPTING DISABLEISM
}

by

Monica Carroccetto, BSW, Ryerson University, 2019

An MRP

Presented to Ryerson University

in partial fulfillment of the

requirements for the degree of

Master of Social Work in

the Program of

Social Work

Toronto, Ontario, Canada, 2020

(C) Monica Carroccetto 2020 


\section{AUTHOR'S DECLARATION FOR ELECTRONIC SUBMISSION OF A MRP}

I hereby declare that I am the sole author of this MRP. This is a true copy of the MRP, including any required final revisions.

I authorize Ryerson University to lend this MRP to other institutions or individuals for the purpose of scholarly research.

I further authorize Ryerson University to reproduce this MRP by photocopying or by other means, in total or in part, at the request of other institutions or individuals for the purpose of scholarly research.

I understand that my MRP may be made electronically available to the public. 


\section{ABSTRACT \\ Disrupting Disableism \\ Master of Social Work, 2020 \\ Monica Carroccetto \\ Program of Social Work, Ryerson University}

The following is a qualitative re-search study and narrative inquiry into service user experiences of mainstream psychiatric 'support' and diagnoses as a child or adolescent. Informed from the theoretical lenses of mad studies, critical disability studies, and anti-colonialism, it critically investigates treatment, response, sanism, agency and support. Through semi-structured interviews with three individuals, this MRP examines how western approaches to mental health (ex: diagnoses, medication, labeling) affect young adults long after being psychiatrized. The findings of this MRP indicate that western mental health experiences are extremely medicalized and limited/limiting and how they perpetuate adultism, sanism and psycho-colonialism. What is revealed from these narratives shows a complex reality, iatrogenesis and damage as well as a battle for acceptance, better care and ultimately understanding. 


\section{ACKNOWLEDGEMENTS}

I would like to begin by expressing my gratitude to the three amazing people that collaborated with me in this re-search. Their narratives have donated so much knowledge and wisdom on the topic at hand and I am forever grateful for our conversations, as they will have a lifelong impact on me and my work.

I would also like to acknowledge all my professors that I had the privilege of engaging with throughout this master's program. Our class discussions, assignments, and collaborative work truly prepared me for the work of this MRP in order to approach it from an impactful, critical way.

My greatest thanks to my research supervisor Dr. Jennifer Poole, for her continuous support, motivation, and positivity throughout this entire year despite all the challenges and hardships. Without her guidance and positive light, this MRP would not be what it is.

To my cohort, thank you for filling me with inspiration, love, and support throughout the year. Lastly, to my parents Ben and Nelia, and to my best friends for the emotional support and constant motivation to help me write this paper. None of this would've been possible without each and every one of you. 


\section{DEDICATION}

I would like to dedicate this paper to all those that are or have been a part of

mental health communities or institutions, as well as those who identify with a diagnosis as well as those who refuse their diagnosis and western approaches to mental health. I

dedicate this to anyone and everyone who has ever felt obscured in the systems, you are not alone. I hope this re-search shines to light that you are seen and you are heard. 


\section{TABLE OF CONTENTS}

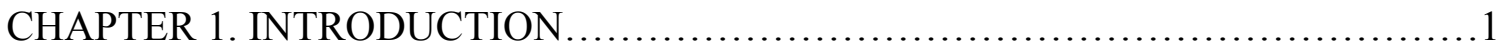

CHAPTER 2. LITERATURE REVIEW..........................................

CHAPTER 3. THEORETICAL FRAMEWORK .................................... 18

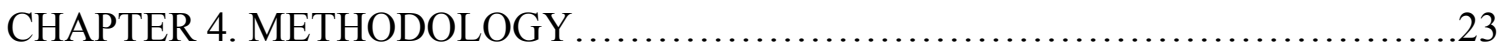

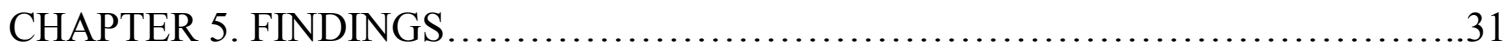

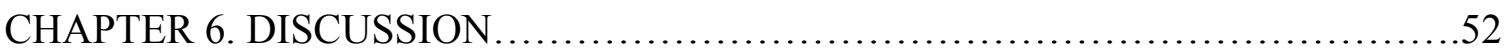

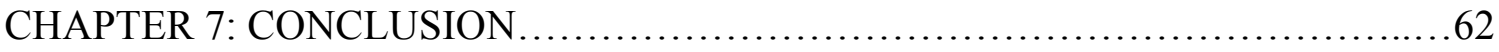

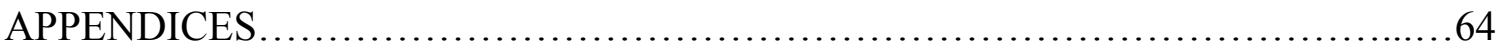

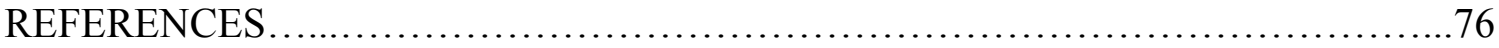




\section{LIST OF APPENDICES}

APPENDIX A- Consent Agreement..............................................64

APPENDIX B- Recruitment Flyer............................................. 70

APPENDIX C- Recruitment Email............................................71

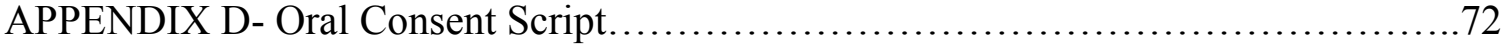

APPENDIX E- Interview Guide............................................... 73

APPENDIX F- Resource List..................................................... 75 


\section{CHAPTER 1. INTRODUCTION}

Prior to beginning this MRP, I had no idea what topic I was interested in or what kind of research I wanted to explore. During our master's orientation, I already felt behind, as many of my peers were already passionate about certain topics and had a good understanding of their research topic. However, throughout this MRP, I realized that this process is not a race or meant to be completed in a linear fashion. When brainstorming about topics that could potentially fit into an MRP, it was difficult as there is an overwhelming amount of injustice, oppression, and marginalization in virtually every aspect of our world today.

What led me towards a topic surrounding mental health was due to personal experiences growing up. Growing up with a western ${ }^{1}$, medical model understanding towards mental health was difficult and isolating. My interest towards mad and disability studies accelerated when I began my BSW at Ryerson, as I realized that healing was different than treatment, and mental health journeys could look other ways apart from a western perspective. This newfound learning and interest led me to pursue these discourses throughout my BSW and through academia and practice. Reflecting on my interests throughout my BSW guided me to choose a topic in mental health for my MRP as it has been of interest and passion for me following my lived experiences.

The specific topic I take up in this MRP revolves around the lived experiences of current adults (aged 18-24) that received a psychiatric diagnosis as a child (between the ages of 4-17); and how this influenced their childhood experiences up until today.

\footnotetext{
${ }^{1}$ I understand western to mean those systems, including political, social, health and mental health systems among others, created by and in-line with european settler colonial ideologies. I do not capitalize this term as per with work by https://www.cjr.org/analysis/capital-b-black-styleguide.php.
} 
My research aims to look at the ways in which western approaches towards mental health influence the well-being and lives of those that have been diagnosed as a child. My research question is 'how do western medical practices work to label young adults that are psychiatrized and what are their impacts?'

This research centers the narratives of three adults and reveals themes of marginalization, resistance, and healing. These three Participants ${ }^{2}$ beautifully narrate their stories of what it was like to be a child with a psychiatric diagnosis and how they sit with these experiences today. The focus of the MRP is to share the different experiences of these individuals through excerpts of their stories of mental health, journeys and interactions with institutions and practices as children.

While being a part of this research, there was a process of unlearning and learning about what it means to have a mental 'illness' and what types of 'treatment' models are supportive or harmful and oppressive. This was an important process in understanding my own mental health experiences as well as those that I practice with in the social work field. I learned that there is no one right understanding or healing in a mental health journey. An individual's experiences are the combination of complex, fluid identities that work to give privilege and oppress in different ways. Having a mental 'illness' is often oppressive and marginalizing due to the way it is understood through a western lens and medical model approach of treatment.

I hope that this research gives insight to those that understand mental health the way I did before entering the social work program.

\footnotetext{
${ }^{2}$ I have chosen to capitalize this word to amplify the importance of all those who shared their time and experiences with me for this re-search inquiry.
} 
I hope that this research contributes to and furthers the focus of anti-colonial, mad studies, and critical disability lens inquiries. I hope that this research sheds light and validity on those that have experienced any type of injustice, whether this was from institutions, people due to their own beliefs around mental health.

This major research paper is not an attack on mainstream forms of mental health treatment or groups but is instead an investigation of individual's experiences of these institutions and processes while growing up. What is revealed from these narratives shows a complex reality as well as a battle for acceptance, better care and ultimately understanding. 


\section{CHAPTER 2. LITERATURE REVIEW}

\section{Epistemological Paradigms and Theoretical Frameworks}

According to Neuman (2013), epistemology is what makes a claim to be true and how we understand knowledge. Epistemology informs what we need to do in order to create knowledge and what it looks like after it has been produced (Neuman, 2013). Evidently, the epistemological perspective that informs research will significantly impact how the knowledge becomes constructed. A paradigm refers to an orientation to research and theory, and is essentially a whole system of thinking including basic assumptions, important questions to answer, and research techniques (Neuman, 2013). Epistemological frameworks and research paradigms intertwine to inform a research study, its findings, and the conclusions drawn.

To organize the literature on their paradigms and theoretical frameworks, I categorized the articles based on the research methodology used. Qualitative methodologies were found in several of the studies I reviewed (Bluhm et al., 2014; Holley, Tavassoli, \& Stromwall, 2016; Landry, 2017; LeFrançois, 2013; LeFrançois, \& Coppock, 2014; Liegghio, 2017; Marquina-Márquez, Virchez, \& Ruiz-Callado, 2016; Walls, Hautala, \& Hurley, 2014). Bluhm et al.'s article (2014) derived from a positivist approach and was dictated from an objective, third person view within research. The other qualitative pieces stemmed from a critical social science paradigm (Landry, 2017; LeFrançois, 2013; LeFrançois, \& Coppock, 2014; Liegghio, 2017; Walls, Hautala, \& Hurley, 2014; Marquina-Márquez, Virchez, \& Ruiz-Callado, 2016) in which there was a value-based activism for human empowerment along with multiple levels of reality existing (Neuman, 2013). 
Other studies reviewed were grounded in quantitative research (Bulanda, Bruhn, Byro-Johnson, Zentmyer, 2014; Quinn, Williams, Weisz, 2015). These quantitative research studies were framed from a positivist paradigm. Positivist social science seeks objective research which can be used to predict general patterns of human activity (Neuman, 2013). Bulanda, Bruhn, Byro-Johnson, Zentmyer (2014) reflected positivist values within their study through their methodology which used pre-test and post-test surveys following a mental health intervention. The surveys developed were designed based on a numerical scale with structured responses. Neuman (2013) states that positivist researchers often use precise quantitative data such as experiments, surveys, and statistics in order to gain results. Moses's (2014) work stemmed from a positivist perspective whereas Leigghio's (2016) developed from a critical paradigm.

All of the literature had many theoretical frameworks that contributed to the knowledge being produced. The theoretical frameworks that were found included critical (Holley, Tavassoli, \& Stromwall, 2016), postcolonial (Landry, 2017), critical disability studies and mad studies perspectives (Bulanda, Bruhn, Byro-Johnson, \& Zentmyer, 2014; LeFrançois, \& Coppock, 2014; Liegghio, 2016; Liegghio, 2017), Indigenous ethical frameworks ${ }^{3}$ (LeFrançois, 2013; Marquina-Márquez, Virchez, \& Ruiz-Callado, 2016; Walls, Hautala, \& Hurley, 2014), and modernism (Bluhm et al., 2014; Moses, 2014; Quinn, Williams, \& Weisz, 2015).

There are strengths and limitations to the knowledge that was produced from the

\footnotetext{
${ }^{3}$ This framework exists to decolonize mainstream theories and methods by adding novel Indigenous perspectives and critical standpoints that encourage researchers of all origins to reflect upon their own positions within the colonial academic and social structures in which they work (Marquina-Márquez, Virchez, \& Ruiz-Callado, 2016 p.25). The goal is to promote ethical awareness within Indigenous research and push the limits for self-determination and capacity building within an academic setting and beyond (Marquina-Márquez, Virchez, \& Ruiz-Callado, 2016).
} 
paradigms and theoretical frameworks as stated above. The positivist frameworks within these studies can be problematic as positivism views reality as patterned with natural order (Neuman, 2013). This approach towards research heavily influenced the epistemology of the topic because this knowledge produced is seen as 'universal' and 'unchanging' since there claims to be only one answer. Within my MRP, I have challenged these notions as I believe that a young adult's experiences within the psychiatry system and the stigma associated afterwards will differ heavily based on their social location and identity in the social environment.

The critical research paradigm has many strengths that are relevant to supporting my MRP topic. Critical research is based in activism for human empowerment (Neuman, 2013) and recognizing that social action is necessary in order for change to occur. Some of the literature that stemmed from a critical paradigm has been helpful throughout my MRP in recognizing the current oppressions that exist while advocating for new approaches to mental health intervention (for example, anti-colonial) as a form of antioppression.

Some of the literature applied modernist approaches to theoretical frameworks. This points out how the epistemological knowledge that currently exists within my topic is often framed towards 'evidence-based' theories that exclude the perspectives of certain populations (for example, marginalized youth). The more progressive theoretical frameworks that often stemmed from a critical paradigm (such as anti-colonial, Indigenous, etc.) provided strengths in the knowledge that was created as a way to offer different approaches to how knowledge is created and shared. 
Approaches of inquiry utilized by scholars I reviewed for this chapter were narrative (Bluhm et al., 2014; Holley, Tavassoli, \& Stromwall, 2016; LeFrançois, 2013) with a data collection method of semi-structured qualitative interviews with open coding, narrative (LeFrançois, 2013) through an auto ethnographic approach, narrative (Holley, Tavassoli, \& Stromwall, 2016) qualitative interviews with open coding, narrative with a data collection method of semi-structured qualitative interviews (Bulanda, Bruhn, ByroJohnson, \& Zentmyer, 2014) phenomenology with a data collection method of focus groups which were transcribed and open coding (Walls, 2014), critical discourse analysis (Landry, 2017, LeFrançois, \& Coppock, 2014;) with a data collection method of secondary data analysis, quantitative surveys (Moses, 2014; Quinn, Williams, \& Weisz, 2015) narrative (Liegghio, 2016) with a data collection method qualitative interviews, focus groups, and participatory action research, phenomenology (Marquina-Márquez, Virchez, \& Ruiz-Callado, 2016) with a data collection method of qualitative interviews followed by open coding, grounded theory (Liegghio, 2017) with a data collection method of semi-structured interviews.

A phenomenological study works to describe the common meaning for several individuals of their lived experiences of a concept or phenomenon (Creswell, 2013). There is an understanding of the 'what' and 'how' of their experiences in order to determine common experiences and develop a universal definition (Creswell, 2013). Narrative research has many forms including studying a phenomenon as well as a methodology used within a study (Creswell, 2013). There is a gathering of data through the collection of stories and ordering the meaning of those experiences (Creswell, 2013). Grounded theory studies move beyond a description in order to create a theory for a 
process or action (Creswell, 2013). The theory is grounded in data that came from the participants (Creswell, 2013).

There are many disciplines that have contributed to the knowledge in the area of childhood psychiatry, mental illness (and stigma), sanism, and ableism. Based on the review of this literature alone, there were clear contributions from social work, disability studies, psychiatry, psychology, community mental health, social science, and Indigenous studies (Bluhm, Covin, Chow, Wrath, \& Osuch, 2014; Bulanda, Bruhn, Byro-Johnson, \& Zentmyer, 2014; Holley, Tavassoli, \& Stromwall, 2016; Landry, 2017; LeFrançois, 2013; LeFrançois, \& Coppock, 2014; Liegghio, 2016; Liegghio, 2017; Marquina-Márquez, Virchez, \& Ruiz-Callado, 2016 Moses, 2014; Walls, Hautala, \& Hurley, 2014; Quinn, Williams, \& Weisz, 2015). It is also important to note that eight of the articles were written or co-written by white-presenting authors (Bluhm et al., 2014; Bulanda, Bruhn, Byro-Johnson, \& Zentmyer, 2014; Landry, 2017; LeFrançois, 2013; LeFrançois, \& Coppock, 2014; Liegghio, 2016; Liegghio, 2017; Moses, 2014; Walls, Quinn, Williams, \& Weisz, 2015) which allowed me to question the extent to which the knowledge being produced is really representative.

Although it is evident that multiple disciplines have contributed to these areas of study, it is important that I acknowledge that the weights of these contributions are not equal. For example, in searching for articles for this literature review, there was much more information on childhood psychiatrization for psychiatric and psychological journals than there was for Indigenous or critical social work journals. This indicates the gaps that exist within the epistemological standpoints of this topic. 
There is extensive research on child psychiatrization, sanism, and mental health, which often fail to incorporate intersectionality and consider alternative approaches towards mental health from anti-colonial perspectives. In my search for anti-colonial approaches to childhood mental health, it was a difficult quest as the amount of information from these perspectives is not as ample. As I will discuss further in this literature review, it is evident that certain forms of knowing have been challenged with white supremist ideologies in regards to what counts as research. This is an important realization as it then raises questions regarding which epistemologies are valued/supported and which are ignored or secondary within mainstream research.

\section{Construction of Knowledge, Exclusion, and Impacts}

While reviewing the literature, it is evident that there were a range of voices that have contributed relevant work within the area of study. However, most of the work stemming from quantitative and positivist research exerted a 'top down' approach in which the researcher is distant from the topic they are studying. The authors and researchers were clinical psychologists, social workers, professors, and sociologists (Bluhm, et al., 2014; Bulanda, Bruhn, Byro-Johnson, \& Zentmyer, 2014; Holley, Tavassoli, \& Stromwall, 2016; Landry, 2017; LeFrançois, 2013; LeFrançois, \& Coppock, 2014; Liegghio, 2016; Liegghio, 2017; Marquina-Márquez, Virchez, \& Ruiz-Callado, 2016; Moses, 2014; Walls, Hautala, \& Hurley, 2014; Quinn, Williams, \& Weisz, 2015). Although it is beneficial to incorporate theoretical knowledge from professionals on a topic, this can lead to epistemological issues as it overshadows the voices of individuals (specifically those who experience marginalization/oppression). 
Many of the authors made suggestions in regards to how to 'improve' mental health interventions, however they do not claim the lived experiences of those individuals. One article that was problematic in the way it reflected the population's issues is found in Quinn, Williams, \& Weisz (2015). The participants were asked to rate their understanding of mental illness, the stigma they received, and the internalized stigma they generated as a result (Quinn, Williams, \& Weisz, 2015). I found this to be problematic as people's lived experiences and feelings are put onto a scale to be measured, with no follow-up on what this means for them and how to make a change. Furthermore, LeFrançois's (2013) autoethnographic narrative discussed her experiences as a worker in child psychiatry and protection institutions, and how she attempted to unwrap her contributions towards child psychiatrization, racism, colonialism, and adultism. However, this is not enough as there is no account of the children who were experiencing these oppressions and how it impacted their lives.

Within the literature, voices included were young adults (Bulanda, Bruhn, ByroJohnson, \& Zentmyer, 2014; Bluhm et al., 2014; Liegghio, 2016; Liegghio, 2017; Moses, 2014) LGB individuals (Holley, Tavassoli, \& Stromwall, 2016), Indigenous youth (Walls, Hautala, \& Hurley, 2014), Indigenous communities (Marquina-Márquez, Virchez, \& Ruiz-Callado, 2016), and adults living with mental illnesses (Quinn, Williams, Weisz, 2015). While this shows that there was a reflection of the population that experiences the topic I am discussing, only the literature that incorporated a critical research paradigm truly reflects on the meaning of the results in their paper and promotes change. 
There was an evident gap in regards to missing voices within my literature review. This included individuals in poverty, many racialized folks, (LGB)TQ+ communities, and those incarcerated. Acknowledging this makes me question how accurate, representative, and justifiable the research that is published can be, and how we consume knowledge based solely on those who are represented in current literature. Quantitative research alone can be marginalizing, as there is a focus on numbers/values as opposed to exploring individual and community experiences to form a holistic understanding of mental health issues and social justice approaches of change. Incorporating the voices of diverse communities will lead to a more wholesome understanding of the topic and will embody several diverse frameworks and research paradigms.

\section{Responding to Epistemological Issues}

I acknowledge that I have lived experience of my MRP topic. As a result, I would like to discuss some of my lived experiences, but also understand that due to my social location (white, middle class, heterosexual female) that my experiences within mental health institutions will differ than those of Participants in the study. Within my MRP, it is not enough to state that I will be working from a critical framework. Critical frameworks are often aimed at 'practicing freedom' in which there is an 'abolishment' of oppression for marginalized populations (Castrodale, 2017). However, populations that identify with madness and disability are often absent within critical frameworks which is often a reflection of ableist systems of discrimination (Castrodale, 2017). Mad studies- informed perspectives unpack disabling sanist oppression and trouble able-bodied/sane privilege (Castrodale, 2017). As a result, it is crucial that I am working within a critical disability 
lens and mad advocacy studies perspective within my MRP. However, even working within these two theoretical frameworks is not the end, as these often emerge and are steeped in whiteness. Thus, it is important to incorporate an anti-colonial framework in order to understand the ways in which psychiatrization is a colonial reflection of our society and how we can work to decolonize critical mental health interventions.

I must also acknowledge the importance of ethics within my research and how I aim to approach the study in regards to my interactions with Participants. I need to be cautious within my approach to research and the methodologies I use. Chilisa (2012) states that research often produces a sameness error by presenting research methodologies that blur any differences in the researched Other. There is a silencing of the less powerful often through mainstream methods of research (Chilisa, 2012). As Potts and Brown (2015) note, research can be a powerful tool for social change or maintaining the status quo. Thus, it is important that I am a part of the former within my research for my MRP in order to address the current epistemological issues that exist within my topic of study; and to prevent perpetuating the current gaps in knowledge.

\section{Summary of Themes}

All of the literature reviewed stemmed from topics of mental health, 'mental illness', and ideas of healing/treatment. I will be discussing the recurring themes of stigma/labelling, psychiatrization (specifically of children), and mental illness.

\section{Stigma and Labelling}

The first major theme I discovered while reviewing the literature gathers around the stigma and labelling associated with mental illness and diagnoses. All the articles discussed this concept, some to a higher extent than others (Bluhm, Covin, Chow, Wrath, 
\& Osuch, 2014; Bulanda, Bruhn, Byro-Johnson, \& Zentmyer, 2014; Holley, Tavassoli, \& Stromwall, 2016; Landry, 2017; LeFrançois, 2013; LeFrançois, \& Coppock, 2014; Liegghio, 2016; Liegghio, 2017; Marquina-Márquez, Virchez, \& Ruiz-Callado, 2016; Moses, 2014; Walls, Hautala, \& Hurley, 2014; Quinn, Williams, \& Weisz, 2015). Mental illness stigma stems from societal misconceptions and stereotypes about individuals labelled with a mental illness or diagnosis. Stigma forces individuals into a box and their personhood becomes replaced by a label; there is an unmaking of a person and the making of a disorder which draws our attention to psychiatrization (Liegghio, 2016). Societal understandings and beliefs about mental health influence the ways in which an individual is able to navigate through life internally and externally (Liegghio, 2017, p.1237).

The literature described internalized and anticipated stigma. When individuals with mental illness internalize the labels they receive as well as anticipate further discrimination in the future, negative feelings about oneself increase as well as discriminatory responses from external sources and institutions (Bluhm et al., 2014; Holley, Tavassoli, \& Stromwall, 2016; Liegghio, 2016; Moses, 2014; Quinn, Williams, \& Weisz, 2015). This then leads to a potential worsening of mental health conditions as individuals then become less likely to seek help, 'treatment utilization', or therapy (Quinn, Williams, \& Weisz, 2015).

Also on the topic of stigma, some of the literature reviewed focused on ways to address and challenge mental health stigma experienced by adolescent populations and in schools (Bulanda, Bruhn, Byro-Johnson, \& Zentmyer, 2014; LeFrançois, 2013; Liegghio, 2017). There are also those who suggested development of a new language to understand 
madness and distress as well as a focus on the collective experiences of psychiatric consumers (Landry, 2017). Addressing stigma can also be understood from an Indigenous lens and through inquiry, into the colonial roots of individual pathology (LeFrançois, 2013; Marquina-Márquez, Virchez, \& Ruiz-Callado, 2016; Walls, Hautala, \& Hurley, 2014). Current social service institutions are sanist and racist in the organization of 'treating' Indigenous children (LeFrançois, 2013).

\section{Psychiatrization}

In addition to stigma, the second theme that was prominent throughout the literature I read was psychiatrization, and ten of the research studies incorporated this theme (Bulanda, Bruhn, Byro-Johnson, \& Zentmyer, 2014; Bluhm et al, 2014; Holley, Tavassoli, \& Stromwall, 2016; Landry, 2017; LeFrançois, 2013; LeFrançois \& Coppock, 2014; Liegghio, 2016; Liegghio, 2017; Moses, 2014; Quinn, Williams, \& Weisz, 2015;). Some of the articles explained the definition of psychiatry and how an individual comes into contact with this institution (Bluhm et al., 2014; Liegghio, 2016). Specifically, psychiatrization refers to the process through which certain people, adult or child, come into psychiatry as a political realm (Liegghio, 2016). A person comes into psychiatry when their body, mind, or emotional distress is constructed as a 'mental illness' or disorder (Liegghio, 2016).

The other literature I read discussed the implications of psychiatrization; the ways in which it influences a child's mental health and social interactions following their experiences (Bulanda, Bruhn, Byro-Johnson, \& Zentmyer, 2014; Holley, Tavassoli, \& Stromwall, 2016; Landry, 2017; LeFrançois, 2013; Liegghio, 2017; Moses, 2014; Quinn, Williams, \& Weisz, 2015). For example, Landry (2017) discussed the power imbalances 
that individuals experience within psychiatric institutions, in which there is often an overemphasis of drug treatments and a lack of focus on service user needs and selfdetermination. Also, LeFrançois (2013) discussed how psychiatrization leads to a further production of mental 'illness' in children in the outlets that should be providing support.

\section{Mental Illness and Disorders}

The third theme emerged from the literature was the discussion of mental illness/disorders (anxiety, depression, suicide). This is an important theme to frame as there is a specific focus on the word 'illness' in many of the sources as opposed to mental health or well-being (Bulanda, Bruhn, Byro-Johnson, \& Zentmyer, 2014; Bluhm et al., 2014; Holley, Tavassoli, \& Stromwall, 2016; Liegghio, 2016; Liegghio, 2017; Moses, 2014; Quinn, Williams, \& Weisz, 2015; Walls, Hautala, \& Hurley, 2014). Eight of the research texts I read focused on the definition or diagnoses of a condition (Bulanda, Bruhn, Byro-Johnson, \& Zentmyer, 2014; Bluhm et al., 2014; Holley, Tavassoli, \& Stromwall, 2016; Liegghio, 2016; Liegghio, 2017; Moses, 2014; Quinn, Williams, \& Weisz, 2015; Walls, Hautala, \& Hurley, 2014). This heavily influences the ways in which knowledge is formed as there is a focus on the individual and their diagnosis, as opposed to those which do not mention specific illnesses, but instead advocate for consumer rights and Indigenous perspectives.

\section{Whiteness in mad and Disability Studies}

The last theme that emerged from the literature review was the prominence of whiteness within the work of mad and disability studies and the lack of anti-racism and anti-colonial perspectives within the literature. A majority of the articles were produced or co-written by white-presenting authors (Bluhm et al., 2014; Bulanda, Bruhn, Byro- 
Johnson, \& Zentmyer, 2014; Landry, 2017; LeFrançois, 2013; LeFrançois, \& Coppock, 2014; Liegghio, 2016; Liegghio, 2017; Moses, 2014; Quinn, Williams, \& Weisz, 2015; Walls, Hautala, \& Hurley, 2014). Of these, some of the authors based their work in a critical disability or mad studies (Bulanda, Bruhn, Byro-Johnson, \& Zentmyer, 2014; LeFrançois, \& Coppock, 2014; Liegghio, 2016; Liegghio, 2017) perspectives, others derived from a modernist perspective (Bluhm et al., 2014; Moses, 2014; Quinn, Williams, \& Weisz, 2015), and others wrote from an anti-colonial lens (Landry, 2017; LeFrançois, 2013; Walls, Hautala, \& Hurley, 2014).

This is an important theme as it is evident that whiteness exists within mad and disability studies. This means that although these frameworks are meant to challenge current injustices and oppressions that individuals with marginalized identities face, mad studies is not representative of those with multiple oppressed identities; such as having a mental 'illness' as well as being Black. The literature is not always accurate in displaying the complex realities of communities that experience intersectionality and oppression through more than one identity. This then limits the research that is produced and continues to silence the voices of those with lived experiences. Although in some of the literature white-presenting authors worked with marginalized communities, it is important to question to what extent collaboration was possible, and whether or not these communities were involved in editing/publishing the work following the study or were they present to give the illusion that that work was inclusive? This influences how we understand mad and disability studies as it is often only represented from white identities and experiences. In this literature review, there were already a limited number of articles 
that worked from a mad and disability studies perspective, and the majority of them that derived from this came from the work of white-presenting authors. 


\section{CHAPTER 3. THEORETICAL FRAMEWORK}

\section{Why mad Studies?}

Mad studies can be described as a project of inquiry, knowledge production, and political action devoted to the critique and transcendence of psy-centered ways of thinking, behaving, relating, and being (Castrodale, 2014, p.52). Within the theoretical framework of mad studies, the experiences of the mad, mentally ill, psychiatric survivors, consumers, service users, patients, neurodiverse, and disabled become narratives of justice and advocacy. Mad studies can allow the silenced to be heard.

LeFrançois tells us that there is currently an "... authoritarian medical model of treatment that creates a culture of care that is alien to the concept of children's participation in decision making” (2008, p.220). LeFrançois's work is important as a means to advocate for a mad studies approach to childhood. Children too have lived experiences in regards to how their diagnosis/diagnoses work to further stigmatize them, perpetuate ideas regarding what is 'normal' within childhood, and how a child should behave within institutional settings. If a child's behaviour does not fit within a normal frame, their diagnosis further perpetuates stigma with respect to their mental health. When a child is given a diagnosis, their personhood becomes replaced by a label (LeFrançois, 2008).

Thus, it is important to apply a mad studies framework to my 're-search' (Absolon, 2019) as a way to challenge labeling and experiences attached to diagnoses. The people who have insight and knowledge into my research question are those that have personal childhood experiences within the psychiatric system and can reflect on these events and their impacts. Using a mad studies framework will help me work from a critical stance. 
Mills (2014) presents a discussion about global mental health and the western approaches to pharmacy and psychiatry. Mills (2014) warns readers about the increasing influence of western notions on child psychiatry, with a focus on the sociopolitical influence this has on an individual's life. Thus, mad studies asks me to investigate the ways in which dominant psychiatric models in our society work to perpetuate experiences of oppression, exclusion, and labeling occurring for those that have been or are still a part of these systems and institutions. Castrodale (2014) specifically suggests that within my research it is important that I critique the ways in which psychiatry and psychology work as ideologies within institutions and other spaces in society to oppress an individual; as well as empower the voices of those for which this is a lived reality.

\section{Why Critical Disability Studies?}

A critical disability lens argues that impairment is the result of exclusionary structures and processes imposed on an individual by a disabling society (Liegghio, 2016). Mad studies and critical disability studies work simultaneously to investigate the medical model and the implications that labelling and diagnoses have on an individual and their experiences in society. In 2020, it is evident that 'diagnosis/diagnoses' are part of a social process utilized to maintain sanist and ableist normativity within society; and how this leads children to feel isolated and stigmatized upon receiving a diagnosis. Liegghio (2016) encourages us to focus on the idea that the primary effect of psychiatrization is the construction of the young person as 'abnormal', and when constructed as abnormal, young people deemed mentally ill encounter various forms of personal and institutional prejudice and discrimination. 
Furthermore, advocates and theorists of critical disability studies emphasize the importance of the word critical. The word 'critical' "... rethinks the conventions, assumptions and aspirations of research, theory and activism in an age of postmodernity. Disability studies were conceived as a modernist project to challenge capitalist conditions of alienation" (Goodley, 2018, p.2). Therefore, current critical disability studies are working to "acknowledge that we are living in a time of complex identity politics, of huge debates around the ethics of care, political and theoretical appeals to the significance of the body" (Goodley, 2018), which pose questions about the usefulness of dominant disability theories. Theorists also emphasize the idea that we must examine the interrelationship between institutionally-produced norms of childhood and the intricacies of children's lives to engage in critical disability studies (McLaughlin Coleman-Fountain, \& Clavering, 2016).

Using this framework is important in my research as it will allow me to explore how institutions and societies 'dis-able' people systemically and socially as well as how a body and impairment can critically be incorporated into the discussions of disability and disablement. Also, critical disability studies is a concept that I believe is important to apply when challenging the ableist notions that live in our society. Since mental illness is often associated with the word 'disability' or 'impairment to functioning in daily life' (McLaughlin Coleman-Fountain, \& Clavering, 2016, p.21), it is crucial to apply this theory into my research, as the two ideas are in relation-always.

\section{Why Anti-Colonialism?}

Due to the dominant, colonial ideologies and practices of our society, it is important to acknowledge that we cannot integrate disability and mad theories into this 
study without examining the ways in which they hold prejudices from western ideologies and understandings of mental health and psychiatry. Discourses of madness throughout history often focus on the medicalization of madness, deviance, and distress, but it has been through an unexamined white lens. Thus, there is a need for anti-colonial resistance in response to psycho-colonialism (Penson, 2019). This is defined as the practice of western disciplines colonizing processes of the Global North through western disciplines alongside business practices such as pharmacy and psychiatry (Penson, 2019). In order to challenge the science-focused perspectives of mad experiences and mental health, it is important to consider the ways in which our understandings of mental health are influenced by, as Penson (2019) notes, psycho-colonialism. Penson (2019) challenges researchers to examine psycho-colonialism, the ways in which we as social workers with one or more privileged identities may be perpetuating this in our own practices, how this influences a service user's experiences in mental health settings and their ability to receive 'culturally appropriate' support.

These are some of the important reasons why I will be applying an anti-colonial framework into my research as the oppression and marginalization that is experienced by psychiatric survivors are due to western ideologies implied in practice that fail to consider cultural and colonial contexts of service users. Also, using this framework will help me to explore and question what 'healing' and 'treatment' means outside of a western context and the implications of its scarcity within current mental health services. Furthermore, I wish to interrupt the unexamined whiteness that exists in mad and disability studies through the use of an anti-colonial framework as a way to provide diverse and intersectional perspectives of mental health. 
There are visible issues of colonialism within mental health services and there is currently a large gap between the number of western mental health services available and the number of mental health services offered that approach practices from Indigenous ways of healing (Nelson \& Wilson, 2017). It is evident in research that,

Mental health practices as they currently exist are rooted in a colonial system and therefore do not adequately take the perspectives of their Indigenous and culturally diverse clients into account. This results in culturally inappropriate services that are inadequate in responding to clients' needs (Nelson \& Wilson, 2017, p.97).

These researchers prove that the current state of mental health systems and practices heavily enforce colonial, Western approaches to 'diagnosis' and 'treatment'. This is not to say that generic mental health services are not at all helpful or effective; but instead this theory asks that I explore the current provision of services and its potential to marginalize and neglect individuals that would benefit from non colonial approaches to mental health and healing (Nelson \& Wilson 2017). As noted above, an anti-colonial lens must be brought to not only mad and critical disability studies but all medical model 'psych approaches'. By doing so, it allows us to have a full understanding of an individual's social location and the ways in which settler identities are privileged in care. These three theories are significant alone yet altogether more powerful when invoked together. 


\section{CHAPTER 4. METHODOLOGY}

\section{Narrative Inquiry}

The research question that guides this study is 'how do western medical practices work to label young adults that are psychiatrized (inpatient and outpatient) and what are their impacts'? Through this research question, I intend to gain a better understanding of how Western approaches to mental health (ex: diagnoses, medication, labeling) affect young adults during and after being psychiatrized. My research will focus on the impact of psychiatric diagnoses on young adults and their experiences in the world that come with having a label attached to their identity.

This research is based in a narrative approach to inquiry. The work of Felton \& Stickley (2018) as well as Cresswell, Friesen, Dueck, \& Gass (2018) have influenced my research and understanding of narrative approaches of inquiry. According to Clandinin and Michael Connelly (2000), narrative is a method that works to allow individuals to transform their personal experiences into personal stories. Narrative inquiry is intended to be a non-pathologizing, empowering, and collaborative approach of inquiry that can allow an individual to objectify their problems, frame the problem within a larger sociocultural context, and create their own stories (Clandinin \& Connelly, 2000). Felton \& Stickley (2018) write,

A narrative is an interpretation of experiences as told by an individual or narrator. Narration is a dynamic activity that creates a new interpretation of events as situated by the person's lived experience. Narrative can create a connection between an individuals' past, present and future and therefore develop a temporal structure for events, providing a context which may have been lost. (p.60)

Furthermore, a narrative approach to inquiry allows for the creation of a narrative that is a product of constructing, deconstructing and reconstructing the self and of our identities (Felton \& Stickley, 2018). Narrative approaches not only allow an individual to 
elicit a story, but also to potentially find new meanings and purpose within their lives that may have gone undiscovered otherwise (Felton \& Stickley, 2018). This means that a narrative approach is not only beneficial in informing readers and outsiders of an individual's truth or experience, but it is also insightful for the person creating the narrative, as it can assist in making meaning within one's experiences.

Biomedical models often exclude personal and cultural experiences of mental illness and it is important to recognize that narratives allow individuals to conceptualize their own unique personal experiences as well as interpret larger sociocultural phenomena (Cresswell, Friesen, Dueck, \& Gass, 2018). Personal narratives can work to “...describe the impact of mental health beyond the biomedical scope of individual deficit and functional impairment" (Cresswell, Friesen, Dueck, \& Gass, 2018, p. 448). It is evident that narratives can be a tool of empowerment for those sharing their stories as well as donating insight to those readers that have preconceived, dominant discourses in mind in regards to the complexities of mental wellbeing.

The reason I chose to use a narrative approach of inquiry is due to its focus on empowering the individual telling their story and giving light to real experiences that are silenced in specific institutions and settings. I believe that narrative inquiry is an effective methodology for my study as it does not search for a specific truth or answer, but instead values the knowledge and stories of those with lived experiences (Cresswell, Friesen, Dueck, \& Gass, 2018). This is essential within my study as many psychiatric survivors/ mad identified individuals remain marginalized within their communities due to the overarching, powerful biomedical model that works to label people and tell them who 
they are, without giving them a voice to speak back to how mental health institutions can be harmful and oppressive.

For my research, the narrative approach asks me to focus on the experiences of the individual, the ways in which they tell their stories and how they believe these experiences to be important in their lives. Felton \& Stickley (2018) encourage me as a researcher to listen to the narrative of the individual telling their story, while not judging. Felton \& Stickley (2018) suggest that not only will I focus on the narrative of the individual and how it makes them feel, but also look inwardly to discover how I am reacting and feeling. This is important as if I am feeling uncomfortable, distressed, or upset for example, we can look towards structural injustices and dominant ideologies that are embedded within society that may be contributing to my discomfort within a narrative.

\section{Ethical Considerations}

Prior to beginning my work of recruitment and data collection, I obtained ethics approval through the Research Ethics Board (REB) at Ryerson University. I submitted a Human Protocol Form to the REB, which asks a detailed amount of questions regarding my proposal to complete research with humans. In this form, I was required to answer questions and describe my research processes such as potential risks/harms that participants may experience before, during, or after the research, how I am collecting my data, how will I ensure privacy of the data after it is stored, and more.

The REB contacted me about six weeks after the first submission of my ethics

proposal. At this point, the REB had thoroughly reviewed my form and responded with requirements and recommendations to my ethics that need to be edited and resubmitted 
before I could begin my recruitment. When I received my REB edit, this is when I was informed that the REB asked everyone doing research to switch to phone interviews to protect researcher and Participant safety due to the COVID-19 pandemic.

Before modifying data collection under these revised circumstances, I had to revise Participant ${ }^{3}$ consents due to differential privacy considerations through a different communication source. My data collection removed all physical contact with my Participants and there was no need to travel outside of their current living space.

\section{Semi-Structured Qualitative Interviews}

The method of data collection I used to gather my research was through qualitative semi-structured interviews. Planned face to face interviews were switched to phone interviews due to the COVID-19. This presented challenges during my research as I had to edit my consent forms, flyers, emails, and REB application in order to approach these interviews in a new way. I was also concerned about doing phone interviews as I felt as though Participants may have been worried about their privacy and confidentiality since we would not have visual access to each other. I also felt that the phone interviews might have limited the ability to develop better rapport with Participants, as once again the visual connection was no longer available. Although, some people may have been more willing to volunteer for a phone interview as opposed to an in person interview as it is quicker, more accessible (does not require them to travel), and allowed them to keep part of their identity private (physical appearance). I was also uncertain about whether or not the pandemic would affect the number of volunteers for my research; I questioned whether or not people would want to participate as a form of socializing during a very isolating time, or whether people would be much too busy and preoccupied with other 
life stressors to participate in a phone interview. Three Participants reached out to me over a two week period. This was after sending a REB approved email to two contacts to share with their networks. Overall and given COVID concerns, I would consider this positive feedback and response time.

I prepared an outline of REB approved questions to ask throughout the interview, which contained both closed and open-ended questions to stimulate meaningful conversations between the Participant and I. For this research, I recruited three young adults (between the ages of 18-24) who had been a part of a psychiatric institution process (inpatient or outpatient) and received a psychiatric diagnosis between the ages of 4-17.

In interviewing these Participants I hoped to better understand how western approaches to mental health (ex: diagnoses, medication, labeling) affect young adults long after being psychiatrized. Some questions that helped to guide the interview included: Can you recall if your relationships with people/places who knew of your diagnosis altered the dynamics of that relationship? Have these childhood experiences continued to influence your current lived experiences with mental illness/potential stigma?

Before the interview, I ensured that I reviewed my notes on narrative inquiry and the three main theories I am basing my research on. Once I connected via phone with the Participants, I went over the consent form again as well as possible risks and benefits, and informed them of the digital device I was using to record the conversation, as well as reminded them that they are free to stop at any time, skip a question, omit any comments that they want removed, and ask any questions. It was important that I ensured their 
safety and still gave them control of the recordings, which was more difficult now through the phone as they did not have physical access to the recorder.

During the interview, it was important for me to allow Participants to talk/comment on topics that may not necessarily be specifically relevant to the questions/topic at hand (Fraser, 2004). It was important that I did not rush the Participants or come to any conclusions that their stories do not make sense or are not relevant. Although I may have had a schedule for the interview which is topic-based, I was not governed by this schedule and instead took the time to really listen to the participants who were voluntarily sharing information with me (Anderson \& Jack, 1991).

After the interview, I notified the Participants when the recorder was turned off and ensured that they were feeling good about the interview, as well as took the time to answer any questions or comments they had afterwards. I also reminded them of my personal contact information should they need or want to contact me after we disconnected. Once we disconnected, I took some notes on the interview such as what I was feeling, which topics were prominent, which questions I should edit, and anything else that may have needed to be altered for the next interview.

\section{Analysis of Data}

Following the interviews, I completed stage 1 of my analysis. After listening to the interviews, taking notes, and transcribing them, I analyzed significant themes and quotes in order to understand the data (Poole, 2020). I completed this thematic analysis by reading through the transcripts carefully, and circling any words/phrases that appear to be meaningful, powerful, or significant. I then transferred the circled words/phrases onto a separate document and grouped together similar words and phrases into their own 
clusters. My goal was to have between five to ten clusters with 'titles' (to describe their themes). I then returned to my transcript to analyze where these cluster themes are appearing. I highlighted and colour coded during this step so that I could view the frequency, their location in the transcript, and potentially any new words, quotes, or themes I may have missed or overlooked the first time.

While completing this analysis, it was important that I remembered I am working with a methodology of narrative inquiry and must also incorporate this into my analysis. It is important that "...each inquirer must search for, and defend, the criteria that best apply to his or her work" (Clandinin \& Connelly, 2000, p.7) and "It is important not to squeeze the language of narrative criteria into a language created for other forms of research" (Clandinin \& Connelly, 2000, p.8). Further, narrative analysis is reluctant to break up the sequence of the narrative as each part is dependent on its location as a whole (Rodriguez, 2016). Thus, the research identifies themes in chronological order (Rodriguez, 2016), which is the order that the Participants tell their story in. So although there were recurring themes in different Participant narratives, it was important for me then to conduct stage 2 and analyze each story individually (Rodriguez, 2016).

Once I completed these steps, I chose some significant quotes from each cluster and then wrote a narrative under each theme that summarized an overarching message that was helpful and relatable to my research and data (Poole, 2020).

As per qualitative analysis, I reflected upon the interview answers of Participants and how answers aligned with, differed, or provided new insights to this research topic. Most of the existing research and studies on this topic rely upon large, anonymous, quantitative data collected in structured surveys (Likert scales/multiple choice). Using 
qualitative methods allowed me to obtain more authentic, real contexts of how individuals are affected by their diagnoses. The "participants narratively come to understand the ways in which their narrative experiences shape their translation of a particular text" (Clandinin \& Connelly, 2000). As a result, the purpose of this research is to bring forward the narratives of those with intersectional, lived experiences and advocate for more qualitative, collaborative research in the future. 


\section{CHAPTER 5. FINDINGS}

In this chapter I present the findings of my narrative re-search and I center excerpts from the stories shared with me by three Participants. The recruitment process of contacting these Participants was all done through email. I sent a recruitment email and flyer to two of my contacts outside of school and asked for them to share it with their networks. Within about two weeks, three people had expressed interest in the study through email response. I interviewed each one, using a REB approved interview guide (see appendix) and listened intently to each story before transcribing the interviews. Importantly, all interviews were about an hour each, and all three Participants used she/her pronouns. I did not have permission to share any other aspect of their social locations, except as told to me in the interviews themselves. (If I were to do this again, I would invite Participants to speak directly to their social locations as part of the interview process. I come back to this in my limitations section of the discussion). As per guidelines in how to do narrative analysis outlined in the methodology chapter, I have purposely used longer sections of the transcripts so as to not break up the narratives related to the key themes below. The following sections are organized into these key themes.

\section{Part 1: Initial Reactions to a Psychiatric Diagnosis}

All three Participants discussed their initial reactions to their psychiatric diagnosis upon receiving the news for the first time. Reactions seemed mostly positive or accompanied by a sigh of relief that they were moving in the 'right' direction towards receiving the supports they needed at the time.

"I was relieved... but scared" 
Participant 1 recalled having a mixed initial reaction upon receiving her first diagnosis as

a teenager.

I think I was relieved because like you can put a name to it [right]. Um...but scared because of kinda like family...stuff. Like uh growing up in like a South Asian Muslim family, mental health isn't like-it's not normal...I was kind of the first person that my parents had ever seen go through like a panic attack or depressive like episodes and um so that was kind of like scary and like nobody really knew how to help [mhm]. And it just felt- felt lonely I guess and I think it made me feel more like ostracized... it just kinda felt like-like I was the black sheep, right [right]. Everyone's normal and then all of the sudden like I have this thing that like some people don't even believe or like is real and it's just kinda like you acting up...it definitely made me feel ostracized and a little bit more lonely... Yea and um...yea I was definitely like I don't know it was-it was weird. I already kinda like knew and I saw it coming what the doctors were gonna say so it in that sense it- the relief came from like them solidifying what I already thought.

Although Participant 1 had both positive and negative feelings regarding her first diagnosis, she had a different reaction to a second diagnosis received later on.

And then the bipolar disorder, um...that was something that was mentioned by my doctor and I was kinda like I rejected that $[\mathrm{mhm}]$. Cause I was like no cause in the media you see these people who are so like- like it's just exaggerated and I know there's people out there that probably are like that but like I only really understood that part of bipolar like I didn't realize there was like different types you know?

Participant 1 also felt that depending on the type of diagnosis she received (and from

whom), it would elicit different initial reactions from those around her;

I was like no I'm like not like- they're saying I'm crazy I'm not fucking crazy like that kind of behaviour, and like and then I went to my therapist and she said it and then my uncle said it and then they were like $\mathrm{k}$ go to a psychiatrist and then the psychiatrist said it and I was like okay I guess I have it as in like they educated me more and I was like okay I guess that makes sense just cause I'm not super manic all the time [right]. Doesn't mean I don't have it so...

"At first I thought it was good"

Participant 2 initially felt positive about her diagnosis, recalling that after receiving it as an adolescent; 
It was good to have the initial diagnosis but okay so I was uh hospitalized when I got my initial diagnosis, so at first I thought it was good because um I was gonna get treatment um and then I could...like I could be better and I could return back to school with full health... But um yea un-unfortunately, that's not how it turned out. But my initial reaction was positive.

Importantly, Participant 2 was very brief in speaking about this initial reaction to the diagnosis, and quickly moved on to what changed over time.

\section{"It's kinda like any other day"}

Participant 3 appeared to have the most accepting first reaction to hearing that she had a psychiatric diagnosis.

(sigh) Honestly like it was-it was just kinda like the-like any other... I didn't really think anything of it like I was kinda like $\mathrm{k}$ whatever like if I have ADHD or if I have a learning disability it is what it is if I don't whatever right? So it wasn't like anything-it didn't really like change me drastically...I sat down with them [my parents] in the room and they were like telling me like you know you have ADHD ... it wasn't like life changing or anything you know it wasn't like I felt like ashamed to be who I am like it was completely like fine for me and like-but that's just like honestly that's just how I am in general like with anything right? Like uh you know but yea like overall it wasn't anything like extremely like significant to me like it was just like $\mathrm{k}$ whatever it's like another day for me.

This Participant thought that her parents were actually more worried about the initial diagnosis (and her reaction) that she was;

I think that my parents were kinda more um like nervous to see my reaction than I was like for-when the psychologist told me but like they're like you know listen like whatever they say like whatever he says to you, you're still like the samewho you are like you're still P3 like you're still the same person like I-they're like it doesn't label you or anything right...

\section{Part 2: 'Medication and Therapy'}

All 3 Participants revealed in their narrative that they were medicated and/or went to therapy following their diagnosis, with mixed experiences of both.

"They were just weird" 
As a young adult diagnosed with a psychiatric disorder, Participant 1 noted:

Uhh I'm not gonna lie I fucking hated therapy...the therapist that was-I talking to like what he was telling me to do I just fucking hated everything like they were just weird and things that like he would say, write the person that you're upset with's name on a card and talk to the- it like it was there. And I was like dude- I already got one issue (laughs). I don't wanna look like I have other things- like it was just stupid... Um- and then the medication...I didn't feel like it was a case specific thing like it almost felt like generic advice [right]. Um... and I kind of expected them to like see kind of what my personality was like, listen to what I was saying and realize that like whatever they were telling me it just wasn't something that was gonna help me...I think mental health and like therapy and medication and everything it's- it's like skincare like things that work for me won't work for you, you know? Everything is specific to you, you're-you're different than me so why would we all have the same you know-routine?

And like I don't know like you get this romanticized uh view from TV shows and movies where like people have these relationships with their therapists and like once they start taking medication they're like yea I feel great like it's helped me so much and like you expect that and when it's not like that, it's kind of just like um...it's disappointing. And you just feel so not motivated to help yourself [mhm]. Um- so yea that's yea. It was really, it was really shitty like when I had that experience with therapy...

Participant 1 also went on to explain her damaging experiences with medication after she

was diagnosed and since, equating the process to being a 'guinea pig'.

With medication- um (sighs) it's almost like a love hate relationship um when I was- at that point- when I was younger than eighteen- they had always diagnosed me with like clinical depression and panic disorders slash like general anxiety. And um at that time they were- you know when I had depression they were giving me- you know like Sertraline, or Lorazepam, and Clonazepam and all those kind of medications and like they were... you kinda just feel like half-like half a person almost... I'm like an excitable person... But like on that it just- it was the opposite, I kinda just felt dreary and like bleh [mhm]... it would literally just knock me the fuck out so like my relationship with drugs is not great and like I don't take anything anymore because, eventually my doctor was like hey you don't have those things actually and the reason why whenever we give you antidepressants you get anxiety and whenever we give you anti-anxiety you get depression is because you actually have bipolar [mhm]. And then like by this point I had taken so many different medications that I was just like...I don't wanna do this anymore, I'm not taking it and I think I had an allergic reaction to something... so I just stopped and ever since then, I've had to figure out like different methods of kinda dealing with stuff which has made me a lot stronger, I think. So my relationship with um medication, at that time when it all first started it was like $\mathrm{k}$ yes, finally something to like help but um eventually just turned into 
another hate relationship, so it kinda like, therapy and medication was reverse, you know? Yea, I just- I hated almost like being like I know- that the thing with mental illness is that like (sighs) you kinda just have to test out these different medications till you find something that works but like for me it's like when you take so many that...it just...it's done so much damage that I just don't wanna have to go through that again... and it took like three years for my doctor to like send me to an actual psychiatrist. So, that also pissed me off cause it's like you don't know what the fuck you're doing but you're just testing testing testing like$[\mathrm{mhm}]$ I'm not a guinea pig I'm a fucking kid.

"The system was starting to fail me..."

Participant 2 also recalled her experiences with medication and therapy while identifying as a child with a psychiatric diagnosis.

I felt like the system was starting to fail me a little bit...more with the treatment. The treatment didn't work as well um...uh yea the treatment was-wasn't working...

Participant 2 went on to discuss the treatment she received while she was hospitalized

and even after her release.

I got the wrong treatment because um they gave me-so the- so they gave me theso they gave me a diagnosis with depression $[\mathrm{mhm}]$. Uh with psych-psychotic features but-but and they wrote it they wrote it down that it was highly suspected of most likely it was bipolar [mhm]. So because it was depression they thought if the depression went away um my psychotic symptoms would stop and um andand my mental health would be you know it would heal. So instead of giving medication they gave me um they gave me uh what is it...talk therapy [mhm]...It was free counselling um and we were just trying to talk things through and my psychiatrist thought um it was what was gonna relieve my...lack of...insomnia, lack of sleep, pressured speech, things like that and also my psychotic symptoms but um it did not.

Participant 2 went on to narrate that it took her years before she received the correct

diagnosis, therefore receiving the right treatment.

They kept me at the wrong diagnosis with bipolar disorder for-for another two more years and then finally was it last year or two years ago...yea I think last year, last year I was finally diagnosed with the correct-with the correct diagnosis... And then she [the psychiatrist] also said that um that the diagnosis didn't matter because the treatment would be the same however I disagreed with that because um... because-because when I just had to deal with bipolar disorder I never had to learn how to deal with my psychosis but since I learned about my 
actual diagnosis, I can actually deal with both the-the mood aspect and the schizophrenia aspect and it was- and after I finally had the right diagnosis I was able to finally be able to figure out how to get the right treatment.

She explained that her current medications and treatments have been helpful, however it took her years to finally get to a supportive place after many misdiagnoses with improper treatment.

\section{"It didn't make a difference"}

Turning to Participant 3, they never received therapy or any other type of treatment besides medication, but it did not work.

In high school I was on medication I don't remember which one I took but like it didn't have an affect on me so it kinda like-I stopped taking it so [mhm]... it didn't make a difference.

She also went on to discuss her second trial with medication when beginning university.

When I was in university like my first two months in there or something I tried going back on the medication but it didn't-it didn't work for me I was actually so stupid like I forgot that you can't-I think it's after like ten o'clock (laughs) you shouldn't be taking the type of medication that I had because you'd be like wired and awake so like you could be like (laughs) getting up at like eleven o'clock, take the medication and then I'd be wired for like literally I wanna say like all day I think it was for like a solid week I was taking them and I was like oh my God like why am I not sleeping? It mind-fucked me (laughs)...

Later on her story, Participant 3 narrates again how her relationship with medication has been in relation to her psychiatric diagnosis throughout childhood and currently.

After that I was like k screw it like I don't need to be doing this just out of curiosity if it doesn't even make a difference. I mean who knows it could've helped me but like as I said today I am where I am as in-like you know I'm completely fine [without it] so, yea.

Participant 3 was not a huge advocate for medication as her personal experiences revealed a lack of helpfulness in relation to her diagnosis. She also felt the medication she was prescribed was incorrect and overall not helpful. 


\section{Part 3: 'I'm a Child but I Deserve Liberty'}

All 3 Participants discussed their belief that children deserve freedom and a say in making decisions and understanding what their diagnoses were. Although they all expressed similar opinions about the importance of a child being involved in decisionmaking processes regarding their diagnosis, some of their experiences were similar and others were very different.

"I didn't know enough about myself, I was a kid living in an adult's world"

Participant 1 discussed her lack of understanding of her diagnosis as a young adult.

I just didn't have the resources and I just didn't know enough about myself and what I was- what was going on with me to deal with it in a healthy way [mhm]. Instead of, you know like when I would get sad or whatever I would just go out and get drunk or something and it would just end up making me aggressive or more depressed the next day...

Participant 1 also discussed a non-medicalized form of therapy she experienced as an adult that was extremely supportive towards her mental health journey. She then related this back to her childhood.

I wish I had that experience so much earlier in life...it was frustrating especially as a kid to have to go to different ones and tell your story all over again.

She explained that much of her childhood experiences were a blur, filled with multiple therapists and medications which all felt decided on her behalf without her having a say about what she wanted to do or engage with, such as this non-medicalized support that she was only able to access once she was an adult and had liberty to make the decision to stop medication and find her own outlets of support that were beneficial for her.

Especially as a kid I always felt so heavy at the end [of therapy] cause...I don't know like the approach to-to therapy when I was a kid it was like...it's so (sighs)...I don't know like just sucked. It's always just like well how does that make you feel? Well maybe you feel like this because of this or like I-I don't know it's like-it's not-it didn't feel like it was coming from me like I didn't feel like I was coming up with anything like- it felt so guided... I don't know how to 
word it properly but it just didn't feel like it was-anything was coming from me... I'd get into that hopelessness kinda state where it's like k no one's ever gonna fucking understand, I'm never gonna understand what I feel... as kid it was always kinda like hey I think I feel like that but they're all like... they would kinda like make it like what they thought and like they think is right.

Participant 1 explains that she felt like she was "a kid in an adult's world" since the day she was diagnosed.

It's like as a kid everything's just so...it's just so unfamiliar, I was a kid living in like an adult's world and like having to deal with all this stuff that like not a lot of other kids my age were dealing with at that time.

Participant 1 concluded with explaining that she wished she received more liberty as an adolescent in relation to understanding and making decisions with her diagnosis because she believed that the only person who can decide what supports they need is the person going through it, regardless of their age.

"It was so strict"

Participant 2 also explains her experiences with having a psychiatric diagnosis as a child

and what freedom looked like for her, beginning with when she was hospitalized.

I had more liberty after I was eighteen but I had no liberty before [right]. Um youI remembered it was so strict you were forced to wake up around eight, you had to eat breakfast at this time, you had to do the exercises, you had to do their programs you know and um...you know you had to do $\mathrm{x}, \mathrm{y}, \mathrm{z}$ every single day until you could leave and it was- I mean you-I got used to it because-because it was a routine but it-there was definitely no freedom when I was hospitalized in the-in the adolescence uh psychiatric ward [mhm]. Um and I don't know if it benefit others because a lot- I remember a lot of other patients were very I guess angry or...I felt like they were very rebellious against it and I-I was kind of rebellious against it too because I didn't wanna wake up so early just to be forced to eat breakfast and do all this stuff I didn't want to do and I was actually really happy when I got out earlier than I should've um so yea definitely, definitely I had no say.

Participant 2 went on to compare her adolescent experiences with her diagnosis to those of when she was an adult. 
I never understood why but I always found that to be a really big difference um...I didn't know whether it was because we were forced to do things or whether it was because the fact that we were adolescents and we were growing um but definitely there was- there was definitely more um not danger but I would say more um...risk towards self and towards others.

Participant 2 discussed that she too, believed in children having the freedom to be a part of decisions made in regards to their psychiatric diagnoses and part of her advocacy for that was shown in her adolescence by rebelling under some of the controls put upon her during her hospitalizations. "It's totally up to you..."

Participant 3 had similar thoughts in regards to advocacy for child's rights and experiences, however, her narrative differs from Participants 1 and 2. Participant 3 tells her story as having a lot of free will as a child in regards to making decisions about her diagnosis.

I think my whole parents mindset was kinda like okay if you wanna take the medication like that's totally up to you like whatever will benefit you ... it was good like I did have lots of free-uh freedom with it.

Participant 3 discussed in passionate detail about how she felt that the need to advocate for children was very important.

Like people's whole mindset is oh like children don't understand this and that well you know maybe if you taught them rather than just saying you don't understand, sit down and have an actually conversation about it with them they might be able to understand even if they don't understand like um as much as like we might because their-their brains are still developing you know?

If someone's taking um if a child is taking medication help them they should first off uh be familiar with why they're taking it, what is the purpose of it, like everything- [exactly]...A lot of parents have just-give their children medication, they don't even know why they're taking it. Like I think that is another thing that people need to-children need to be aware of you know [mhm]? They just notice oh I'm taking this for no reason that's why-well I'm just taking it because my parents told me-well why are you taking it you know? 
Participant 3 seemed to have a very strong opinion about this theme as she revealed that the liberty she had as a child with a psychiatric diagnosis led to a positive experience in her mental health journey.

\section{Part 4: Negative Reactions to Diagnosis and Rejection of Diagnosis by Others}

All three Participants expressed that they experienced negative reactions from others after receiving a psychiatric diagnosis as a child. Not only did all three Participants experience this in school settings as well as through family and friend relationships, but there was also a rejection of their diagnoses by certain groups and institutions.

Responses from the School Community

\section{"I didn't tell anyone in my high school"}

Participant 1 recalled that she did not tell anybody about her psychiatric diagnosis outside of her family when she was a child.

I don't think I actually told anybody in my high school [mhm]. I think I kept thatuh- I was very good at going to school and pretending like nothing was going on at home and like being normal [mhm]. If you were a kid who was always joking around and seemingly kinda happy go lucky, if you were upset one day people would kinda be like what's your problem? What's wrong? What's wrong? What's going on? Why are you like this? Like what the fuck is up with her [mhm]? Umand I really hated that cause then I felt like I couldn't feel the way I needed to [right]...like high school's so judgy and it's...I definitely didn't... I wasn't open about it at that point um and then um when I started getting panic attacks that was definitely something that I was very embarrassed about... I would just be so embarrassed and like just constantly thinking like $\mathrm{k}$ all these people are probably like getting scared and freaking out like why is she acting so fucking crazy like...so...

Participant 1's felt the need to hide her diagnosis from her friends and peers due to the fear of being judged. She explained that "you just start to suppress and suppress and suppress and then it just gets worse and worse...". And when symptoms of her illness 
were revealed to others at school, there was the judgment arising of her acting 'crazy' and

'weird' which led to social isolation.

I was a kid living in like an adult's world and like having to deal with all this stuff that like not a lot of other kids my age were dealing with at that time [mhm]... I think when we were kids, it wasn't [common] [yea]. At least in my high school it didn't seem like-it was like kids just weren't open about it...

It's saying your diagnosis basically-it's something that you have that other people don't [exactly]. Do you know what I'm saying? Like you were diagnosed with it, that person wasn't, that person wasn't, that person wasn't, you're the only one.

Participant 1 concluded that the negative reactions she experienced in school settings

came from her peers.

"People called me crazy"

Participant 2 had a very similar story to Participant 1 in which she did not tell anyone

outside of her family about her psychiatric diagnosis for a major fear of being

marginalized from her peers.

While I was hospitalized when I got that diagnosis um I knew someone who-who told me about how she lost her friends from having that diagnosis so I didn't want to have that same thing so that's why-that's why I didn't say anything [at school] $[\mathrm{mhm}] \ldots$... $\mathrm{Um}$ and she told some of her friends and yet her friends left her and it freaked me out and I remember just thinking oh my goodness I can't tell my friends about it $[\mathrm{mhm}]$. And especially the psychosis part I mean I was just scared out of my mind myself about the psychosis and I could not allow um my friends to know about it you know? Unfortunately though the thing was is that everyone [at school] knew I had a mental health issue [right]. So, I felt-it felt like they knew already um it-it- they knew already to begin with so it wasn't- I didn't- I didn't really need to admit to it because they knew by the way-by how they um by how I reacted- by how I um by my behaviour...there was definitely less people (shuffling) talking to me [mhm]. Um- I-I know for a while after I got out of the hospital people called me crazy despite my friends trying to hide it because you know people are really bad at whispering (laughs)... so I knew they knew about something happening and um actually I had what happened was-was also that a teacher told my tutor, which the tutor told me that um she didn't have uh...she doesn't have much going on in life [mhm]. Um or actually it's more of um she's not gonna make it in life. That's-that's exactly what he said actually [wow]. I have it written somewhere cause I- I was so upset that day. 
I've been hearing like that teacher saying that I don't have much going on in life which my tutor told me and he's like- and then she asked me what was going on um so um clearly it felt like there was definitely going-things going on but I stillI still remember when teachers would just tell me oh yea she's not gonna make it or not gonna do much.

A psychiatrist at $=$ mental health organization $=$ also said something very similar but I mean I've been getting a lot of those comments throughout my life [mhm]. I don't know if I'm immune to it but there's a part of me that kind of says- that kind of thinks no like that kind of disagrees [mhm]. Um but there are also ones that kind of think oh I do have this illness maybe they're right, I do sometimes succumb to that...again stigma of not being able to do something because I just have an illness.

I definitely- had a lot of uh a lot of um...people saying oh you shouldn't do this because you have this or you don't have the skills for this so-so it's...um.... andand just adding the fact that you know I have mental health issues it really just added (bang) it just kinda sealed the deal I guess it kinda just made it a lot worse.

Participant 2 explained in further detail why she never told anyone at school the truth about her diagnosis.

I didn't want people to start thinking of me differently [right]. Um... but you know people already did so I guess it-I mean it didn't really work out anyways but I didn't want people to start thinking of me differently... what I was going through, it-it kinda felt taboo to me.... Only four of my friends knew I was in the hospital...they knew it wasn't physical but they wouldn't say it um but I never told them my diagnosis or anything I just said I was sick...Um but I know I asked them not to tell and I know they didn't tell...but again um again once everyone kind of found out it was-it was- it kinda went downhill from there.

Participant 2 concluded that within the school setting, she received negative reactions from both her peers as well as staff members in the institution such as her teachers.

\section{"The teacher thought I was incompetent"}

Participant 3 narrated a similar story to those of Participant 1 and 2 in regards to receiving negative treatment in the school system, however she communicated that the negative treatment came from staff in the school.

The only negative experience that I got was I actually felt like the [resource] teacher thought I was incompetent and dumb, so like I remember that I would be called down there, it was coming time to apply to- for universities and I basically 
was like I do not like this teacher like she makes me feel like I'm incompetent being able to apply to university like and I- I can say- I can assure you that like it was the same situation with my sister too like we both very felt like we were more-not like discriminated but like discouraged like it was like we didn't havelike we weren't capable of going to university you know [mhm]? Like she would always try to like get me to do um take an aca-sorry an applied class rather than academic and she'd always try to encourage me to like go lower.

She would talk to me like I was stupid, like she would talk to me slowly, be like are you okay to do this like she was babying me I was like k like I'm fully capable of understanding what you're saying to me... if I was a resource teacher I would not speak to someone as if they were stupid like that's the reaction I got from her in high school.

And in terms of like the people support like high school was yea again they weren't-it was kinda-yea I guess it was more so negative like looking back on it now like I-like before doing this interview like I was questioning like I was wondering like what kind of questions you were gonna ask me and I was like you know what I don't have anything negative to say but like looking-thinking of it now it's like shit like that kind of is like a crappy situation like if you think about it (laughs).

Despite this situation at school, Participant 3 was quite open about her diagnosis with her

friends and family and did not receive negative reactions from them.

I was so open about it like I- was whatever. No, no honestly nothing negative that I can think of right now like I didn't really have like a bad relationship with anything-in a situation like that it is a part of who you are so you accept it and you embrace it and- I think it depends on the person themselves and how they wanna go about it so like me personally like I didn't let it bother me you know like I have such a- either way like I don't even have like a major case of it but like Ithere's still-I have been like oh my God I'm having such like an ADHD moment (door closes) or someone's been like you-you have an ADHD moment but other than that like no my relationships have been good...

Participant 3 raved about the importance of support from external groups such as family and friends as well as internal acceptance of her diagnosis as a means of healthy coping skills and managing her diagnosis.

Responses from the Mental Health Community

"Hey you don't have that anymore you actually have this" 
Participant 1 and 2 experienced negative reactions within the mental health community as well. Their experiences displayed differential reactions to different diagnoses as well as a diagnosis hierarchy for children. Participant 1 discussed how originally she was diagnosed with depression and anxiety as a child but the doctors realized years later that she was actually dealing with bipolar disorder.

Eventually my doctor was like hey you don't have those things actually and the reason why whenever we give you anti-depressants you get anxiety and whenever we give you anti-anxiety you get depression is because you actually have bipolar.

Participant 1 recalled being frustrated when finding out she was misdiagnosed and at that point gave up on medication and therapy for the rest of her childhood due to past negative experiences. She believed she was misdiagnosed due to the inability of past doctors and therapists to actually get to know her on an individual and personal level which led to a generalization of treatment.

"I don't know what makes them think one illness is worse from the other"

This part of Participant 1's narrative relates to Participant 2's experience of being misdiagnosed, and in the narrative below, she reflects on why she was misdiagnosed. Participant 2 also received a misdiagnosis of depression with psychotic features as a child.

I was diagnosed from fourteen-fifteen...So, what happened was um so I had that for two years and then I went to university um away from home [mhm]. And then my illness evolved [mhm]. So basically they finally realized the severity of it and um diagnosed me with bipolar three or four years later once it got to university um...but realized...but then it kinda happened again when my uh-uh psychosis wasn't going away um they thought it was- they- they thought it was actually this new-this actual illness called schizoaffective.

They kept me at the wrong diagnosis with bipolar disorder for-for another two more years...I think last year, last year I was finally diagnosed with the correctwith the correct diagnosis [right]. Because again, even, well actually it was because my psychiatrist says you know it's-it's very difficult to diagnose because 
for one...it's being diagnosed within the schizophrenia spectrum is...is considered one of the-one of the more worst case scenarios [mhm]- she called it.

Compared to bipolar itself. And then she also said that um that the diagnosis didn't matter because the treatment would be the same however I disagreed with that because um... because-because when I just had to deal with bipolar disorder I never had to learn how to deal with my psychosis but since I learned about my actual diagnosis, I can actually deal with both the-the mood aspect and the schizophrenia aspect and it was- and after I finally had the right diagnosis I was able to finally be able to figure out how to get the right treatment.

Um...from my medical files, they always said they diagnosed this but they believe I have this...my psychiatrists that I've seen have-have an inkling at least or have thought about it as well um the reason they didn't change it I don't know [mhm]. I don't really know why they didn't change it. I know- I know some of them-actually I did remember one time that it was in a family group meeting that someone preferred diagnosed [to diagnose a person] with borderline [disorder rather] than bipolar because bipolar- they considered bipolar worse than borderline which I thought was extremely offensive [mhm]. Um, and my momand my father and my mother was there just um to even-was there- luckily to even tell her off saying that it was a very offensive thing to say-not-not just as a just as a person but also as a medical professional and the mental health community.

So you know I think there- again I believe there's stigma with mental health diagnoses which I think is ridiculous but I think that's also- that's a big factor in what-what pushed me back from getting the right diagnosis and I think that's also what pushes a lot of people back from um...uh from people just giving the right treatment um because you know um I don't-it could be from- I don't know what makes them think one illness is worse from the other [right]. So I know that um being in the mental health system and being a part of the mental health community I'm also a part of a mental health um non-profit organization [mhm]. So being with all these other people we- we learn that they always treat the illness that's considered less severe [right]. And then when that illness is kinda-dissipates or those symptoms dissipate and that more major illness keeps going forward then-then they treat that and then that's when they diagnose that even though unfortunately that's a-even though that's the one that should be treated first um I don't know why they do it but it-it sounds like it definitely has something to do with the stigma um and um yea and it- and it definitely just doesn't have to do with just regular community it definitely deals with the mental health community as well.

Participant 1's and 2's narratives illustrate that misdiagnosis can actually come from the medical community. As both of their stories showed, there was a preference of diagnosing them with anxiety and/or depression as a child even though they were 
suspected to have bipolar disorder because there is a stigma around specific illnesses that are seen as 'worse' or 'more difficult to deal with'. It is left up to the medical professionals to decide which ones they prefer to diagnose the Participants with.

\section{Rejection: Mental Illness is not for Kids}

On the opposite end of the spectrum, all three Participants also experienced a rejection of their diagnosis from others growing up.

"She's such a faker"

Participant 1 expressed that some of her peers in high school did not believe that she could have a mental health diagnosis, which is why she was also reluctant to reveal her diagnosis. Not only was there a fear of being labelled for having it, but for her there was also a fear of rejection that no one would believe her.

I think I thought a lot that they'd be like oh like she doesn't have that like she's just acting like she's such a faker blah blah blah um just because I was a certain way at school and different at home... I've always been paranoid of people saying like oh she's just like acting her life is fine why is she upset like why is she depressed...

Mental health is definitely not a big thing when you're a kid, when you're a kid people are just like oh you're happy go lucky, you're happy, you have nothing to worry about, like you really don't hear about kids- with depression and like anxiety disorders and bipolar disorders like you really didn't hear about it [mhm]. When -when I was younger and my high school and definitely in my family that was never something that we like we knew about.

[Even] Guidance counsellors had no fucking idea about this stuff. I remember I had actually gone to my guidance counsellor about this what I was going through [yea]- And she was just fucking lost (sighs).

She explained that the guidance counsellors were not informed about mental health issues and did not provide any support for her, which served as another form of rejection of her illness. During her childhood, she had the experience that mental health was not believed 
to be real amongst children especially; which was enforced by people she interacted with at school as well as some family members.

I think it was hard for my parents with that word [diagnosis] too because they were kinda just like snap out of it get over this get over this phase get over this phase but it's like dude it's just not a phase you need to-cause like again for them using the word diagnosis it's for things like cancer... so, here I am trying to get comfortable with that [diagnosis] and I'm surrounded with people who you know reject it... it was hard to get comfortable with it and to get used to it when you have society who's like no dude get over it and your family who's like no dude get over it.

"There's been a lot of people who don't believe me either"

Participant 2 also experienced this reaction.

It's kind of funny cause there's- um there's been a lot of people that don't believe me either... So, I get this double-edged sword where it's either people believe me and they call me crazy or- or people just don't believe me in general and then they kinda discard me um so when I was at my-so after my hospitalization um I had problems with my mental health um, I decided to go to my school psychologist um to see because my talk therapy wasn't working um so I checked the school psychologist and um he said I had no problem at all. He also believes that um I didn't have- that my diagnosis- I didn't have mental health and I was just going through very like teenager...moods he called it or teenager... uh I didn't- I didn't know he just said I was going through a teenager phase [mhm]... and it would go away. Um which is probably even more heartbreaking than someone calling me crazy to be honest.

That was kind of the last time I went to any mental health professional until Iuntil it kind of exploded in university because- added stress and the fact that it wasn't-well...the-my illness kind of um got worse because it hasn't been treated it kind of just gotten a lot bigger until it kind of exploded and that's kinda what happened and then that's when people started recognizing oh she has a problem oh okay now-now we should do something about it instead of when I was I was in high school they could've nipped it in the butt and then I could've-it could've made my life a little easier I think.

When mental health professionals and others invalidated her experiences and labelled them as simple teenage problems, Participant 2 lost faith in the system. She believed that if her experiences were more validated as a child, her illness might not have worsened as much as it did in adulthood. 
Participant 1's and 2's narratives display that there was a rejection of their mental illness as a child from multiple sources such as family, peers, and staff members within school; due to the bias that their experiences were just a part of regular life. This invalidation caused both Participants to lose hope in receiving support from mainstream institutions, which also led to a worsening of their mental health when transitioning to adulthood.

\section{Rejection: Yours Isn't Real Enough}

"You're not important enough to get assessed"

Participant 1's and 2's experienced rejection of their experience. Participant 3 also experienced rejection of her diagnosis but hers was because she was not deemed to have a 'real' enough illness to receive the support she wanted at the time from her educational institution.

I felt extremely like I was discriminated for it [at school]... my university experience with it wasn't really great, they weren't really helpful; they were very neglectful of it... the school was not very good in terms of like the experience I had with having ADHD or whatever they weren't really nice towards it- I didn't really feel like I was- I was- I wasn't not like necessarily valued but I feel like the school like especially like in any institution I just felt like the academic world was not very-I wasn't treated very well with it... the university overall I felt like theyI didn't get any support when I needed it like at all like they were just- I don't what was-was wrong with it but yea that's how I pretty much felt (laughs).

Participant 3 went on to discuss her experiences at the beginning of university in relation to her diagnosis, explaining that she began to feel extremely overwhelmed with the work and needed support from the school.

I actually decided okay I wanna go get assessed and that's when I actually realized the school that I went to-they were-it was just like a shit show... I went to go talk to the people that help students with like learning disabilities and stuff essentially right [mhm, yea]? And I was like... is it possible that I get reassessed this year and they basically turned me down and said you're not uh- you're not important enough to get assessed or we don't have the time for you and I was just like- that's when I felt like I was discriminated against because they were helping other people but they weren't willing to help me 
I had my psychologist documentation, I had my IEP, and I was like here, I have, like I have something I'm like, I'm-I'm willing to get tested again if you like whatever but they were like no like we don't have time for that at the moment I think, I don't know it was- it was weird I was like k whatever I wasn't- I wasn't happy about it but yea.

Participant 3 explained that she did not receive the support she needed in her academic setting in high school or university.

\section{Part 5: Non-Medicalized Practices}

"It was the best experience I've had with any type of therapy"

Towards the end of their stories, some Participants discussed engaging in nonmedicalized practices to support their mental health journeys. Participant 1 narrated that for many years she did not have confidence in any forms of mental health support that deviated from western, medical model norms. However, after exhausting all of her other options, many of which she deemed as unhelpful, she decided to try Reiki therapy.

A lot of people would be like okay that's a bunch of mumble jumble bullshit and I kinda thought that too before I did it [mhm]. It's a- it's more of like a spiritual thing... so she places her hands over different body parts so your head, your neck, your shoulders, your arms, your core, your legs, um and she kinda like it's about chakras [right]... I had gotten into such a meditative state... I didn't even think it was possible you don't know how many like meditation classes at my yoga studio I went to and I never felt like that, my mind was always racing.

And after she talks to you about what she feels and like what she felt from different parts of your body and like all this stuff...she was saying this stuff to me that I had never had a therapist understand... and like, I actually like started to cry because I was so like...oh thinking about it right now I have chills and I'm getting overwhelmed like it was the first time-throughout therapy I always just wanted somebody to understand me without having to say everything-and that's exactly what this was.

Like it was so overwhelming to have somebody understand and like (sighs) be able to like relay that kinda thing and like talk to me about that it was just-again like it was just so spiritual and like it was just a deeper connection that I was able to build it was amazing. 
It was something that I never thought I would need but it was amazing [yea]. Like- it was just- it felt so good to have somebody know what's going on and like know how I felt... It was the most peaceful and light that I've ever felt I think... I always felt heavier in therapy...especially as a kid.

I think it was very holistic um she went over like-like I obviously went over what um what...diagnoses that I had had... but I...I don't know like it wasn't like oh you're bipolar so this is why you're doing this you know what I mean it was more of like a you're a human and like this is why you feel like that, you know what I'm trying to say it wasn't always about... whatever I had... there was just no labels it was just like I was- I was feeling like this because of things that I had to deal with and you know what that's a part like your mental health there's a part of it but it's not-it's not who you are... it wasn't like a this is your thing this defines you, let's talk about that... like it was awesome it was the best experience I've had with like any type of therapy.

After this experience, she felt hopeful and confident that there were methods to mental health support that strayed from mainstream medical, western approaches. She did not feel judged or labelled by her diagnosis as she had often felt growing up in mainstream treatment settings, but instead had a spiritual and holistic experience, which provided her with a new outlook. She mentioned that nobody or no institution growing up informed her of these types of non-medicalized healing methods. This was an experience that she found through personal research and years of trial and error with other treatments.

\section{"It actually helped a lot with my psychosis"}

Participant 2 also mentioned that she has engaged in non-western approaches to mental

health for support. She engaged in tapping which is known to be a type of ancient

Chinese acupuncture that works to physically alter the brain, energy system, and body.

There was this thing called tapping that kinda helped sometimes because it does bring me back to the moment um I don't use it quite often though because itthere's a specific um kind of method you have to go through um like certain places you have to tap first because it's supposedly um helps you get down to centre in the right way... there are [also] some sort of meditations I will try um and breathing techniques um uh I'm trying to think of something else but other than those two I haven't thought of anything that would-that really helped my health uh other than a lot of journaling I find writing helped me a lot um especially with journaling um because it helped me um be able to figure out how 
I'm feeling [for sure]. And it actually helped a lot with my psychosis so really journaling was a big part that was aside from uh counselling and medication and hospitalization but um really helped with my-with symptoms.

Participant 2 also mentioned that she was never introduced to any other forms of nonmedicalized mental health practices and therefore she had to discover this on her own. Although journaling may not be classified as a spiritual or non-medicalized practice, it is separated from mainstream medical practices, and was a practice that was individualized to support her.

Participant 3 expressed that she rarely engages in western approaches to mental health and the practices she does engage in would not be considered western or nonmedicalized, but instead just a positive outlook towards her diagnosis as well as healthy daily routines such as eating healthy, getting enough sleep, maintaining stable relationships, and so on.

I would just say I'm a fairly like mellow person to begin with like I think my whole mindset is just like be positive like be appreciative be grateful like I think a lot that's why like I didn't need it [treatment].

Participant 3 also acknowledged that she identifies as having a mild case of ADHD, which may contribute to reasons as to why she does not engage in many practices or treatments. She said that it had been years since she's been on any medication and feels that she is better able to cope with her diagnosis without it, and it has made her stronger to learn personal coping skills to help her manage her daily life. 


\section{CHAPTER 6. DISCUSSION}

In the findings chapter, I organized the narratives along thematic lines, demonstrating the key themes of: the participants' initial reaction to their diagnosis, their experiences with medication and therapy, their ability to practice rights, the negative reactions and rejection they experienced with their diagnosis, and their familiarity with non-medicalized mental health practices. I purposely stayed close to the Participants' words, working with longer excerpts of their narratives to demonstrate their responses, feelings and in-depth reactions. There is a lot to be learned from these three narratives. In this chapter, I will bring my theoretical and methodological lenses back in to make sense of these learnings and what they could mean for social work practice.

\section{A Medicalized Experience}

This research focussed on the Participants' lived experiences of receiving a psychiatric diagnosis during childhood or adolescence. I pulled from a mad studies lens to centre those with mental health lived experiences (Castrodale, 2017) and to value their stories and what they believe are best practices for themselves.

In the beginning of the findings chapter, it was revealed that all three Participants were 'treated' for their diagnosis immediately after receiving it. This reflects how enforced and prevalent the medical model is. Using a mad studies perspective, Castrodale (2017) argues we must counter, problematize, and nuance dominant psy-narratives on disability and mental health. The fact that mainstream medication and therapy were introduced to all three Participants as their only options by doctors/psychiatrists is to be problematized. Castrodale (2017) also notes the influence of Big Pharma in the limitations of options. 
And yet, none of the Participants favoured medication. The narratives of Participants 1 and 3 are extremely similar to those in the findings of Bluhm et al. (2014). These authors found that many adolescent Participants felt that the use of medication worked to stigmatize them more, affected their interpersonal relationships, added to a loss of self-control and sense of identity while on the medication (and was overall just unhelpful). Although Participant 2 presents a more positive medical model narrative, she experienced misdiagnoses. Again in keeping with mad studies perspective, she knew what type of support she needed from the beginning but was turned down by medical professionals and given treatments that lined up with their knowledge, not her lived experiences.

Furthermore, Participants 1 and 3 also engaged in mainstream forms of therapy and counselling dictated by medical practitioners in which they had negative experiences, especially throughout adolescence. Bluhm et al.'s (2014) study also mirrored similar results in which many adolescents would forgo therapy after negative experiences and gained support through self-empowerment and other non-medicalized ways of healing.

Goodley (2018) notes a critical disability lens challenges us to question capitalist institutions that create stigma and alienation for those that are deemed to have a disability or impairment of any sort. The Participants expressed feeling alienated through medication and therapy although it's 'intention' was for them to 'recover' and integrate themselves back into productive society. Whether it was through the medications that made them feel like less of a person or through therapy, there was a sense of seclusion from those deemed as not having a mental illness.

\section{Adultism}


The next theme in the findings show that all three Participants believe in being a part of decision making processes in regards to their mental health as a child. Although one Participant experienced this, the other two Participants advocated for child rights because they experienced the complete opposite. LeFrançois (2013a) and Liegghio (2016) suggest the problem is because of adultism or oppression experienced by children and young people at the hands of adults and adult-produced/adult-tailored systems. Young people's mental health, distress, and wellbeing are often understood and treated according to the worldviews of adults, but this is not necessarily welcome or healthful.

In adultist practices, children and youth and their lives become objects acted upon by adults instead of agents and subjects uniquely positioned in childhood to inform and act in their own right as social actors (Liegghio, 2016). This leads to unequal power balances and the discrimination occurring at both the individual and systemic levels (Liegghio, 2016). This is another form of sanism that youth face because now not only do they have a psychiatric diagnosis, but they are removed from decision-making in their journeys. There is little research from both critical disability and mad studies on children's experience of labelling and treatment. They are often believed to be not disabled enough or not mad enough because they are young (Liegghio, 2016).

The official mad studies term for this is called epistemic injustice. It is the idea that a person is wronged in his or her capacity as a knower, which is a useful framework for interrogating the subjugation of mad knowledges (LeBlanc \& Kinsella, 2016, p.61). Sanism, which is a deeply embedded system of discrimination and oppression, is also an underlying component of epistemic injustice. Sanism assumes a pathological view of madness, which can be attributed to psychocentrism: the notion that pathologies are 
rooted in the mind and/or body of the individual, rather than the product of social structures, relations, and problems (LeBlanc \& Kinsella, 2016, p.61). Thus, sanism marginalizes mad communities and contributes to epistemic injustice. LeBlanc and Kinsella (2016) suggest that epistemic justice requires us to make room for diverse knowledges that force radical questioning of taken for granted assumptions.

The most dominant theme that emerged from the findings was the discussion of negative reactions and rejections that the Participants experienced following their diagnosis. This is where mad, critical disability, and anti-colonial theories come into play.

Bulanda, Bruhn, Byro-Johnson, \& Zentmyer (2014) discuss the idea that common stereotypes of mental illness (viewing these communities as incompetent or dangerous) leads to prejudice from these beliefs, which as a result forms discriminatory behaviour against the 'out group' which can include actions such as bullying or social exclusion. The findings are in line with this as all the Participants were afraid to reveal their diagnosis for fear of isolation from their social circles as well as being treated differently by larger social institutions. Since these Participants' narratives were based on their childhood and adolescent experiences, most of the discrimination occurred at the school level as that is a main source of interaction and community for a child. However, the fact that some of the findings revealed that they also experienced this at an institutional level shows the prevalence of the medical model in institutional settings. This is known as sanism which is a form of oppression and a belief system that works to strip away the dignity and livelihood of a person that has received a psychiatric diagnosis, medication, or any other form of 'therapy' (Meerai, Abdillahi, \& Poole, 2016). Furthermore, there is 
an overrepresentation of Black-identified individuals in the mental health system that works to maintain injustice and historic discrimination against these communities (Meerai, Abdillahi, \& Poole, 2016, p.23).

Landry (2017) explains that mental health diagnoses often come from the works of researchers, doctors, and 'professionals'. The Diagnostic and Statistical Manual of Mental Disorders (DSM-5) is an example of this idea. Those who have created this manual (psychologists, psychiatrists) often are not representative of those with lived experiences that live with multiple identities (age, race, gender). So once these diagnoses and their symptoms are decided by a higher power, a practice is developed in the medical and mental health community about which diagnoses are 'preferred' to be treated over others. Thus, negative responses exist within the mental health community as there is bias and connected to specific diagnoses over others.

\section{Beyond 'Psycho-Colonialism'}

This brings me to the analysis of my last finding in which the Participants discussed how they have understood and gained control of their mental health in nonmedical ways. The research suggests there is often a lack of race or ethnic specific services for those seeking mental health support (Holley, Tavassoli, \& Stromwall, 2016). And yet the issue was that medicalized support was neither 'enough' or useful to these Participants. They needed to and wanted to access support outside that model and when possible, it was useful to them. All of the Participants who did engage in non-medicalized mental health supports had to find these supports on their own. It was not a type of support that was suggested for any of them through their doctors, psychiatrists, hospitals, and other main forms of medical settings. 
We can see how the medical model is inherently white and colonial, but mad and disability studies are too. Western ideologies universalize mad experiences which marginalize those that do not identify as white and do not have these so-called universal experiences (Meekosha, 2011). For example, living mad while Indigenous is an entirely different experience from living mad while white. This is why anti-colonial work within mental health spaces is crucial as a shield against psycho-colonialism and why mad and disability studies are not enough on their own in understanding the experiences of marginalized communities that are a part of the mental health system. Mad and disability studies can also be secular and lack the voices of oppressed and marginalized populations (Meekosha, 2011). Thus, not only are mainstream mental health systems white but so are the theories that supposedly go against these institutions to give communities alternate spaces to identify with.

Working with these theories was useful but in my own re-search, there was a replication of this white-out in the questions that were included in the interview guide. As noted in the findings chapter, if I could do the work again, I would have centered narratives about race, social locations, madness and medications/therapy as central to disrupting disableism.

\section{Language and Internalized Sanism}

Throughout their narratives, Participants used words such as 'crazy' quite frequently to describe themselves and to relay how others described them at certain points in their lives. From the literature, we know this word is loaded and can signal internalized sanism and stigma. Internalized stigma refers to the idea that an individual with a mental 'illness' begins to absorb (or internalize) the negative messages or 
stereotypes about mental health onto themselves (Pérez-Garín Molero, \& Bos, 2015).

Perlin (1990) also argues that sanist practices include the use of the term 'crazy' or

'psycho'. When this language is unexamined, this can lead to more negative outcomes for individuals and the perpetuation of these sanist practices in their daily lives.

Damaging Medications and Iatrogenesis

All three Participants discussed varying levels of physical, emotional and identity

damage experienced by taking medications for their situations/diagnoses. In keeping with much of the literature informed by Disability Studies and mad studies, this finding is central. Participants make clear that not only are the medications prescribed damaging but the process of 'getting it right' is also damaging. As Participant 1 stated, medical professionals "test out these different medications till you find something that works" and “that also pissed me off cause it's like you don't know what the fuck you're doing but you're just testing testing testing like- [mhm] I'm not a guinea pig I'm a fucking kid". This led to fear of what they might be prescribed next, or going on and off different medications. It also led to identity damage with Participants not sure who they 'were' anymore and aware of how they were 'different' people on the meds. The official term for this is iatrogenesis which describes the damage done by a supposed 'cure' (Peer \& Shabir, 2018). What this MRP demonstrates is identity as well as physical and emotional iatrogenesis.

\section{Limitations}

As discussed in my earlier chapters, this study contained limitations, some of them being a part of the COVID-19 pandemic. This alone limited my contact and relationships with the Participants as we connected through the phone as opposed to in 
person which may have influenced the information I received from them and their willingness to narrate their story over the phone to a stranger.

Also, my research was age specific as I only accepted Participants between the ages of 18 to 24 . I was unable to conduct research with children who are currently psychiatrized (and under the age of 18) as this required a longer research ethics review and under the time constraints of this MRP, I was unable to move forward with that idea. Thus, current childhood experiences may differ from those who I interviewed who are now all legal adults. Also, childhood experiences with psychiatry may look different for those who are now beyond the age of 24 .

I also acknowledge that this study only represents three narratives of those that have lived experiences within this topic, and it is not representative of entire communities or populations with similar journeys. Although the three narratives revealed are extremely relevant and important in moving towards anti-oppressive social work and social justice, there are many other narratives that have not yet been told. This MRP chips away at the surface of a deep rock of lived experiences by millions of people all over the world. In reference to this, all three narratives discuss childhood experiences with psychiatry in Canada, and thus this research does not refer to the systems and lived experiences outside of a Canadian context.

Lastly, this research was limited to a discussion of the sanism individuals experienced with their mental health diagnoses, medication and treatment. Yet, these individuals all come with multiple, fluid identities that contribute to their experiences of sanism, discrimination and oppression on many levels. I wish I could say more about all those kinds of intersectional sanism experiences, and I wish I had more pages to do so. 
Individual social locations deeply influence their access to resources, the quality of services, and overall experiences. Intersecting identities that work to form social locations include variables such as gender, race, religion, culture, socioeconomic status, and more. This research is limited in the fact that most of the Participants did not discuss these identities voluntarily, and as a researcher, I take responsibility for not incorporating important questions regarding social location into my re-search goals, interview guide, and re-search questions. The Participants lived experiences are all greatly influenced by these identities and this research was limited in its analysis of how all of their social locations played a role in their mental health experiences.

\section{Implications for Social Work}

Although this paper stems from a mad perspective, disability studies, and anticolonial lens, it is important to acknowledge that the social work profession has historically been known for being quite the opposite of these frameworks. So as much as I have worked to stray away from a western, medical model approach to understanding mental health throughout this research, it is important to acknowledge the ways in which social work remains complicit in these institutions and continues to contribute to oppression of and within mental health communities.

Also, this research is not a 'be all end all' in my anti-oppressive and social justice work as I continue on in the field of social work. In fact, this is barely the start. I am still deeply interconnected to the devastating colonial influences that social work has had on marginalized communities. It is difficult to situate myself in regards to how I can truly be anti-oppressive and advocate for marginalized communities when the profession itself is deeply embedded in colonial frameworks and institutions. It will take a lifetime of 
unlearning and relearning what I have come to know throughout my life about mental health; about sanism and colonialism.

As Poole describes (Hasan, 2018), sanism and colonialism rely on each other in order to perpetuate and replicate. This can show up anywhere; right in our faces all the way to our relationships with others and work practices. Thus, the fact that sanism and colonialism are interwoven means that I must acknowledge both and understand how I am actively partaking in perpetuating these ideologies and practices in the workplace and my personal life.

As social workers, we must work to identify these instances of oppression within the communities we collaborate with. Beyond identifying, we must work from anticolonial, critical disability, and mad studies lenses in order to challenge the dominant systems that we interact with that work to oppress and marginalize communities. 


\section{CHAPTER 7. CONCLUSION}

I believe that this work is part of the literature that seeks to better understand the complex and diverse experiences of those with psychiatric diagnoses. Through this work I have realized that there is currently not enough literature on this topic, and many texts that do exist are not representative of marginalized communities that experience oppression through one or more identities. How many of us understand mental health and the mental health system, myself included before my own lived experiences along with this research, is often so misguided and distant from those with lived realities.

My research question asked how a psychiatric diagnosis influences a person's childhood experiences and how this sits with them currently as adults. It is evident from this research that receiving a diagnosis has its upsides and downsides. A diagnosis can reveal who is privileged and has access to resources that suit their needs and who becomes more vulnerable and oppressed. I hope that this research spreads a message to not only those a part of the mental health community, not only those that refuse to identify, not only those that identify as mad, but also to those who may think they do not identify with these experiences or this research at all. We may not realize how woven together and intricate all of our lives are and how our actions and behaviours influence those in our communities that we may have never even met.

This MRP is significant to anybody and everybody. I hope I was able to communicate this throughout my paper as well as emphasize that it is our responsibility to show kindness, love, and compassion always. We all live perplexing lives and many times we are fighting battles that cannot be seen with the naked eye but this does not make them any less valid or relevant. You may think that you cannot change the world or 
break down these powerful western, capitalist institutions; where do you even start? I often struggle with this at a personal and social work level and I try to remind myself that transformation does not have a rulebook. In this sense, if we work from an anti-colonial, mad studies and critical disability lens in our personal lives and reflect this onto those we interact with, it becomes the start of something larger and structurally transformative. Change starts within and how we apply these changes into our communities is where real social justice and action begins. 


\section{APPENDICES}

\section{APPENDIX A- Consent Agreement}

\section{Ryerson University Consent Agreement}

You are being invited to participate in a research study. Please read this consent form so that you understand what your participation will involve. Before you consent to participate, please ask any questions to be sure you understand what your participation will involve.

\section{DISRUPTING DISABLEISM}

REB 2020-057

\section{INVESTIGATORS:}

This research study is being conducted by me, Monica Carroccetto, from the Master of Social Work program at Ryerson University and Jennifer Poole, an Interim Associate CoDirector, Graduate Program and Associate Professor at Ryerson University.

If you have any questions or concerns about the research, please feel free to contact me at mcarroccetto@ryerson.ca or Jennifer Poole at jpoole@ryerson.ca

\section{PURPOSE OF THE STUDY:}

This study is designed to explore the relationship between mental illness stigma and labels in childhood and their influences on several aspects of life (school, family, friends, etc.) as a result of diagnosis/diagnoses that a person has received as a child. The number of participants being recruited for this study is 3 . Eligibility criteria include being between the ages of 18-24 and having received a diagnosis within a psychiatric space between the ages of 4-17. You are ineligible for this study if you are not between the ages of 18-24 and/or you did not receive a psychiatric diagnosis between the ages of 4-17. The results of this study will contribute to my Major Research Paper, as I am a graduate student and this research is in partial completion of my degree.

\section{WHAT YOU WILL BE ASKED TO DO:}

If you volunteer to participate in this study, you will be asked to do the following things:

- Sign a consent form in order to have a full understanding of the study and what is involved

- Connect through a phone interview

- This one-time interview will take a maximum of 1-2 hours from start to finish 
- Sample questions include

- Was your diagnosis revealed to school members/faculty? If so, how did this impact your academic ability and performance?

- Demographic data being collected includes age, email address, phone number, and address which will be collected through email

- By participating in this study, you will have access to research findings through Ryerson's Digital Repository

\section{POTENTIAL BENEFITS:}

- Potential benefits include raising awareness about mental illness stigma and reflecting lived experiences,

- Contributing to a major research paper that will be published in Ryerson's library archives,

- And encouraging other voices to come forward to form a sense of community within the research topic being explored to share their experiences which potentially hold new insights

I cannot guarantee, however, that you will receive any benefits from participating in this study.

\section{WHAT ARE THE POTENTIAL RISKS TO YOU AS A PARTICIPANT:}

- Psychological risks

- During the interview there is a risk that you may experience psychological discomfort while disclosing experiences about interactions with psychiatric institutions. The risk of this happening is medium risk as it involves recalling past experiences, which may have been negative, unpleasant, or traumatizing.

- This risk is raised in the consent form and will be revisited with you before and after the interview. Before the interview you will be reminded that you can skip questions, take a break, or discontinue the interview permanently as well as withdraw from the study at anytime. You will also be made aware of resources they can access in order to receive psychological supports. After the interview, I will again check-in with you and offer information about how to access support services. I will also advise you that you can contact me at anytime for information about accessing support services.

- Social risks

- You may experience feelings of embarrassment or being exposed due to the transparency that sometimes occurs within these types of interviews. Revealing these lived experiences to an interview/person you are unfamiliar with may cause you to have these feelings. Thus, the risk of this happening is medium risk.

- This risk is raised in the consent form and will be revisited with you before and after their interview. Before the interview you will be reminded that you can skip questions, take a break, or discontinue the interview permanently as well as withdraw from the study at 
anytime. You will also be made aware of resources they can access in order to receive psychological supports. After the interview, the I will again check-in with you and offer information about how to access support services. I will also advise you that you can contact me at anytime for information about accessing support services.

- Personal identity risks

- There is a low/minimal risk of your identity being discovered, as I am the only person that has access to your demographic information.

- No personal information or identity will ever be included in the completed research publication. All demographic data will be stored securely in password protected files and destroyed in a timely manner (see section on Data Storage). You will be asked to review/edit you interview transcripts to ensure you are comfortable that the information does not identify you to potential readers. You will have three weeks to review your transcript after the interview and once those transcripts are ready, I will put them on a secure Google document to review individually. I will not be providing you with the draft MRP, but you will have access to the final copy via the digital repository. If you do not provide input within a certain period, it will be assumed that you are satisfied with the transcripts/paper as they are. Pseudonyms will be used in the publication. You will only be identified as a 'participant'.

- Dual-role risk

- You may have a previous or current relationship with me. This poses the risk of feeling forced/pressured to participate or complete the study even if you do not feel comfortable or willing to do so.

- If potential participants have a relationship with me, they will be asked not to participate in the study.

\section{CONFIDENTIALITY:}

- I will first be contacted by you, as you will be, at first, anonymously recruited by the snowball method. However, beyond recruitment you will cease to be anonymous as you will be made known to and interact with me through a phone interview. At this point and beyond, your identity will remain confidential.

- Signed consent forms, audio recorded interviews, interview transcriptions, and contact information (names, email or phone number) will be collected. All digital data will be stored electronically under password protected files solely in my computer.

- All data will only ever be kept by the single researcher Monica Carroccetto.

- The audio recordings will be password protected on the audio device and uploaded to password protected audio files. These audio files will be deleted once the transcriptions are completed which is anticipated to be within a week of the interview being audio-recorded. Only myself and my supervisor will have access to transcripts until submission of the MRP. At this point, the transcriptions will be kept as password protected files up until the final draft of the paper is completed and submitted to the School of Social Work of Ryerson University this is anticipated for mid-August 2020. Once the paper is submitted to the 
School of Social Work of Ryerson University the transcriptions will be destroyed. The transcriptions are only kept until final publication for the purpose of my being able to review them and write my paper.

- I will be your collecting name, phone number, and/or email address during the recruitment process so that I can arrange interviews during the research process. The information will be kept confidential and securely stored electronically with password protection, which will be deleted before the publishing of the research paper. No personal information will be revealed in the research paper, instead, false names will replace real names. I will also be collecting your age to confirm you are within the eligible criteria I am seeking for my research.

- You can indicate your preference of whether or not your real name is used in published material

- In certain circumstances, there may be limits to the protection of your confidentiality. I may be required to disclose confidential information regarding you to the appropriate authorities when required by law or if there is a special duty to report. For example, I am required by law to report to the proper authorities any suspicions of child neglect or abuse that they may come across during the duration of their research. In addition, as a social work researcher, I am required to breach confidentiality in the event that I find out that you pose an imminent harm to yourself or others.

\section{INCENTIVES FOR PARTICIPATION:}

You will not be paid to be a part of this study.

\section{COSTS TO PARTICIPATION:}

You may have to use your cell phone minutes (as a part of a cell phone plan) to complete this interview.

\section{COMPENSATION FOR INJURY:}

By agreeing to participate in this research, you are not giving up or waiving any legal right in the event that you are harmed during the research.

\section{VOLUNTARY PARTICIPATION AND WITHDRAWAL:}

Participation in this study is completely voluntary. You can choose whether to be in this study or not. If any question makes you uncomfortable, you can skip that question. You may stop participating at any time. If you choose to stop participating, you may also choose to not have your data included in the study. The final date to withdraw participant data is up until the time of submission which is expected to be around the end of August. Your choice of whether or not to participate will not influence your future relations with Ryerson University or the investigators Monica Carroccetto and Jennifer Poole involved in the research.

Your involvement may be terminated by me without regard to your consent if there is high/severe psychological/emotional/social anxiety or trauma that occurs before, during, or after the interview. 


\section{DATA STORAGE:}

Signed consent forms, audio recorded interviews, interview transcriptions, and contact information (names, email or phone number) will be collected. All digital data will be stored electronically under password protected files in my computer. The audio recordings will be password protected on the audio device and uploaded to password protected audio files. All data will be stored on Ryerson's secure Google Drive. Interviews will be transcribed immediately after completion and digital audio files deleted. Then, only myself and my supervisor will have access to transcripts until submission of the MRP. These audio files will be deleted once the transcriptions are completed which should be within a week of the interview being audio-recorded. Transcriptions will be kept as password protected files up until the final draft of the paper is completed and submitted to the School of Social Work of Ryerson University (expected date of completion is August 2020). Once the paper is submitted to the School of Social Work of Ryerson University the transcriptions will be destroyed. The transcriptions are only kept until final publication for the purpose of me to review them and finish writing my paper.

\section{DATA DISSEMINATION:}

The anticipated dissemination of the data will be in the form of a major research paper which is part of the requirements of completing the Master of Social Work program at Ryerson University. The final paper will be submitted to the School of Social Work and stored at the University such that it could be accessed by other students. It is not anticipated that this paper will published beyond this submission. Participants will be given access to the MRP through Ryerson's Digital Repository. https://digital.library.ryerson.ca/islandora/search/*03A*?f[0]=mods_extension_degree_d epartment_ms $\% 3 \mathrm{~A} \% 22$ Social $\% 20$ Work $\% 22$

\section{QUESTIONS ABOUT THE STUDY:}

If you have any questions about the research now, please ask. If you have questions later about the research, you may contact Monica Carroccetto, Master of Social Work student at Ryerson, mcarroccetto@ryerson.ca or supervisor Jennifer Poole jpoole@ryerson.ca

This study has been reviewed by the Ryerson University Research Ethics Board. If you have questions regarding your rights as a participant in this study please contact:

Research Ethics Board c/o Office of the Vice President, Research and Innovation Ryerson University 350 Victoria Street Toronto, ON M5B 2K3 416-979-5042 rebchair@ryerson.ca

\section{CONFIRMATION OF AGREEMENT:}


Your signature below indicates that you have read the information in this agreement and have had a chance to ask any questions you have about the study. Your signature also indicates that you agree to participate in the study and have been told that you can change your mind and withdraw your consent to participate at any time. You have been given a copy of this agreement.

You have been told that by signing this consent agreement you are not giving up any of your legal rights.

Name of Participant (please print)

Signature of Participant

Date

I agree to be audio- recorded for the purposes of this study. I understand how these recordings will be stored and destroyed.

Signature of Participant

Date 


\title{
DISRUPTING DISABLEISM: PARTICIPANTS NEEDED FOR RESEARCH ON CHILDHOOD EXPERIENCES WITH PSYCHIATRIC DIAGNOSES REB 2020-057
}

\author{
Are You:
}

- Between the ages of $18-24$

- A part of a psychiatric institution process (inpatient or outpatient) at any point as a child between the ages of 4-17 (ex: received a psychiatric diagnoses from a medical professional; not preferred whether or not medication is involved, therapy, clinical visits, etc.)

If you answered yes to the above noted questions you are invited to volunteer in this study of exploring the stigma and impacts of labeling associated with psychiatric diagnoses on childhood and lived experiences. This study is looking for a total of 3 participants and is being completed as a part of a major research paper for the Master of Social Work program at Ryerson.

You will be asked to take part in a semi-structured phone interview.

Your participation will involve one interview that will last for a maximum of 1-2 hours.

If you are interested in participating in this study or for more information please contact:

Monica Carroccetto mcarroccetto@ryerson.ca

Supervisor: Jennifer Poole, Interim Associate Co-Director, Graduate Program and Associate Professor

This research study has been reviewed and approved by the Ryerson University Research Ethics Board 


\section{APPENDIX C- Recruitment Email}

\section{Ryerson}

University

REB 2020-057

\section{Email template}

$\mathrm{Hi}$,

My name is Monica Carroccetto. I am a student at Ryerson University in the Master of Social Work program. Please contact me if you might be interested in participating in a research study.

This research is being done as part of my Masters project. The focus of the research is to explore the stigma and labeling associated with mental illness upon receiving a psychiatric diagnosis as a child.

To participate you need to be between the ages of 18-24 with any kind of psychiatric diagnoses received as a child (4-17). This study is looking for a total of 3 participants.

If you agree to volunteer you will be asked to participate in a semi-structured interview through the phone.

Your participation will involve one interview that will last for a maximum of 1-2 hours.

This research has been reviewed and approved by the Ryerson University Research Ethics Board.

This study is supervised by Jennifer Poole (Interim Associate Co-Director, Graduate Program and Associate Professor at Ryerson University). If you are interested in more information about the study or would like to volunteer please stay in touch by email at mcarroccetto@ryerson.ca. 


\title{
APPENDIX D- Oral Consent Script
}

\section{Ryerson}

University

\section{Oral Consent Script}

\section{REB 2020-057}

\begin{abstract}
"Thank you for your interest in participating. Before we start the interview, I will review the consent form with you and give you the opportunity to ask questions, then I will ask you for your oral consent. This will be digitally recorded. If you do not wish to give consent or proceed, we will end the process immediately and all info you have shared will be deleted immediately. May I turn on the recorder and begin reading through the consent form? (Yes/no). (If yes, read through consent form). Now I have finished reading through the consent form, do you have any questions? (yes/no). Do you give your consent to participate in this interview? (yes/no) Do you give your consent for the interview to be audio-recorded? (yes/no) Thank you.
\end{abstract}




\section{APPENDIX E- Interview Guide}

Disrupting Disableism: Semi-Structured Interview Questions

\begin{tabular}{|c|c|}
\hline Topic & Questions \\
\hline Beginning/Introduction & $\begin{array}{l}\text { How old were you when you received a diagnosis? } \\
\text { Did your diagnosis come with treatment, therapy, } \\
\text { medication, etc.? } \\
\text { Do you believe there were positives/negatives to } \\
\text { receiving this diagnosis? } \\
\text { What role did your family play (if any) after receiving } \\
\text { this diagnosis? } \\
\text { What were your feelings/understandings of the } \\
\text { diagnosis? } \\
\text { Was your diagnosis helpful during treatment or did it } \\
\text { lead to labeling? }\end{array}$ \\
\hline Experiences & $\begin{array}{l}\text { Who was your diagnosis revealed to (ex: family, } \\
\text { friends, school, etc.)? } \\
\text { Can you recall if your relationships with } \\
\text { people/places who knew altered the dynamics of that } \\
\text { relationship? Does the idea of labeling come into play } \\
\text { with this? } \\
\text { When (or if) did the labelling start (ex: right after } \\
\text { your diagnosis, during medication, etc.) } \\
\text { Do you believe there were positives/negatives to } \\
\text { exposing this diagnosis to others? } \\
\text { Are there any other practices you involved yourself in } \\
\text { as a form of 'treatment' that were considered non- } \\
\text { traditional coming from a medical perspective? } \\
\text { How did these practices help/hinder the ways in } \\
\text { which you experienced your diagnosis? } \\
\text { How do you feel about the word 'diagnosis'? }\end{array}$ \\
\hline
\end{tabular}




\begin{tabular}{|l|l|}
\hline $\begin{array}{l}\text { Conclusion/ Closing the } \\
\text { Interview }\end{array}$ & $\begin{array}{l}\text { Have these childhood experiences continued to } \\
\text { influence your current lived experiences with mental } \\
\text { illness/potential stigma? }\end{array}$ \\
. & $\begin{array}{l}\text { How has the idea of labeling influenced your overall } \\
\text { lived experiences and where you are today? } \\
\text { Did your diagnosis shape your overall childhood } \\
\text { experiences and interactions with others? } \\
\text { How do you understand your diagnosis today in } \\
\text { comparison to how you did as a child? }\end{array}$ \\
\end{tabular}




\section{APPENDIX F- Resource List}

\section{Toronto Distress Centre}

31 Adelaide St E, Toronto, ON M5G 1B1

(416) 408-4357

https://www.torontodistresscentre.com

info@dcogt.com

\section{Gerstein Crisis Centre}

100 Charles Street East, Toronto, ON M4Y 1V3

416-929-5200

http://gersteincentre.org

admin@gersteincentre.org

Youthdale Psychiatric Crisis Services

227 Victoria St, Toronto, ON M5B 1T8

(416) 363-9990

http://youthdale.ca/en/index.php 


\section{Reference List}

Absolon, K. (2019). Indigenous Wholistic Theory: A Knowledge Set for Practice. First Peoples Child \& Family Review, 14(1), 22-42. Retrieved from https://fpcfr.com/index.php/FPCFR/article/view/370

Anderson, K. and Jack, D. C. (1991) Learning to Listen: Interview Techniques and Analyses, in S. Berger Gluck and D. Patai (eds) Women's Words: The Feminist Practice of Oral History, pp. 11-26. New York: Routledge.

Bluhm, R. L., Covin, R., Chow, M., Wrath, A., \& Osuch, E. A. (2014). "I just have to stick with it and it'll work": Experiences of adolescents and young adults with mental health concerns. Community Mental Health Journal, 50(7), 778.

Bulanda, J. J., Bruhn, C., Byro-Johnson, T., \& Zentmyer, M. (2014). Addressing mental health stigma among young adolescents: Evaluation of a youth-led approach. Health \& Social Work, 39(2), 73-80.

Castrodale, M. A. (2017). Critical disability studies and mad studies: Enabling new pedagogies in practice. The Canadian Journal for the Study of Adult Education, 29(1), 49.

Chilisa (2012). Whose reality counts? Research methods in question. In Indigenous research methodologies (pp.73-96). Los Angeles: SAGE.

Clandinin, D. J., \& Connelly, F. M. (2000). Narrative inquiry: Experience and story in qualitative research (1st ed.) Jossey-Bass.

Creswell (2013). Five qualitative approaches to inquiry. In Qualitative inquiry and research design ( $3^{\text {rd }}$ ed) (pp. 69-110). Los Angeles: SAGE.

Cresswell, J., Friesen, D., Dueck, K., \& Gass, C. (2018). Struggles vs. symptoms: The narrative approach to mental illness. The European Legacy, 23(4), 447-451. 
Felton, A., \& Stickley, T. (2018). Rethinking risk: A narrative approach. The Journal of Mental Health Training, Education, and Practice, 13(1), 54-62. doi:http://dx.doi.org.ezproxy.lib.ryerson.ca/10.1108/JMHTEP-06-2017-0043

Fraser, H. (2004). Doing narrative research: Analysing personal stories line by line. Qualitative Social Work, 3(2), 179-201. doi:10.1177/1473325004043383

Goodley, D., \& Runswick-Cole, K. (2018). The body as disability and possibility: Theorizing the 'leaking, lacking and excessive' bodies of disabled children. Scandinavian Journal of Disability Research, 15(1), 1-19.

Hasan, M. (2018, April 27). Sanism and Anti-Oppressive Social Work Practice. [Video File]. Retrieved from https://www.youtube.com/watch?v=C24xus-pStU

Holley, L. C., Tavassoli, K. Y., \& Stromwall, L. K. (2016). Mental illness discrimination in mental health treatment programs: Intersections of race, ethnicity, and sexual orientation. Community mental health journal, 52(3), 311-322.

Landry, D. (2017). Survivor research in Canada: 'talking' recovery, resisting psychiatry, and reclaiming madness. Disability \& Society, 32(9), 1437-1457.

LeBlanc, S., \& Kinsella, E. A. (2016). Toward epistemic justice: A critically reflexive examination of 'Sanism' and implications for knowledge generation. Studies in Social Justice, 10(1), 59-78. doi:10.26522/ssj.v10i1.1324

LeFrançois, B. A. (2008). "It's like mental torture": Participation and mental health services. International Journal of Children's Rights, 16, 211-227.

LeFrançois, B. A. (2013). The psychiatrization of our children, or, an autoethnographic narrative of perpetuating First Nations genocide through 'benevolent' institutions. Decolonization: Indigeneity, Education \& Society, 2(1).

LeFrançois, B. A. (2013a). Adultism. In T. Teo (Ed.), Encyclopedia of critical psychology (pp. 47-49). New York, NY: Springer Reference. doi:10.1007/978- 1- 
4614-5583-7

LeFrancois, B. A., \& Coppock, V. (2014). Psychiatrised children and their rights:

Starting the conversation. Children and Society, 28(3), 165-171.

doi:10.1111/chso. 12082

Liegghio, M. (2016). Too young to be mad: Disabling encounters with 'normal' from the perspectives of psychiatrized youth. Intersectionalities: A Global Journal Of Social Work Analysis, Research, Policy, And Practice, 5(3), 110-129.

Liegghio, M. (2017). 'Not a good person': Family stigma of mental illness from the perspectives of young siblings. Child \& Family Social Work, 22(3), 1237-1245.

Marquina-Márquez, A. Virchez, J., \& Ruiz-Callado, R. (2016). Postcolonial healing landscapes and mental health in a remote Indigenous community in subarctic Ontario, Canada. Polar Geography, 39(1), 20-39.

McLaughlin, J., Coleman-Fountain, E., \& Clavering, E. (2016). Disabled childhoods: Monitoring differences and emerging identities. London: Routledge. doi: $10.4324 / 9781315795898$

Meekosha, H. (2011). Decolonising disability: Thinking and acting globally. Disability \& Society, 26(6), 667-682.

Meerai, S., Abdillahi, I., \& Poole, J. (2016). An introduction to anti-Black sanism. Intersectionalities: A Global Journal of Social Work Analysis, Research, Polity, and Practice, 5(3), 18-35.

Mills, C. (2014). Psychotropic childhoods: Global mental health and pharmaceutical children. Children \& Society, 28(3), 194-204.

Moses, T. (2014). Determinants of mental illness stigma for adolescents discharged from psychiatric hospitalization. Social Science \& Medicine, 109 (Complete), 26-34. 
Nelson, S. E., \& Wilson, K. (2017). The mental health of Indigenous peoples in Canada: A critical review of research. Social Science \& Medicine, 176, 93-112. doi:10.1016/j.socscimed.2017.01.021

Neuman (2013). The meanings of methodology. In Social research methods: Quantitative and quantitative approaches (7th ed., pp. 91-124). Boston: Pearson Education Inc.

Peer, R. F., \& Shabir, N. (2018). Iatrogenesis: A review on nature, extent, and distribution of healthcare hazards. Journal of family medicine and primary care, 7(2), 309 .

Penson, W. J. (2019). Psycho-colonialism: colonisation in mental health (Doctoral dissertation, University of Central Lancashire).

Pérez-Garín, D., Molero, F., \& Bos, A. E. R. (2015). Internalized mental illness stigma and subjective well-being: The mediating role of psychological well-being. Psychiatry Research, 228(3), 325-331. doi:10.1016/j.psychres.2015.06.029

Perlin, M. L. (1990). Psychodynamics and the insanity defense: "ordinary common sense" and heuristic reasoning. Nebraska Law Review, 69(1), 3.

Poole, J. (2020, 25 February). Now what? Transcript and analysis [PowerPoint slides]. Retrieved from https://courses.ryerson.ca/d21/le/content/296758/viewContent/2806905/View

Potts, K. \& Brown, L. (2015), Becoming an anti-oppressive researcher. In S. Strega \& L. Brown (Eds.), Research as Resistance: Revisiting critical, Indigenous and antioppressive approaches (2nd ed.) (pp. 17- 42). Toronto: Canadian Scholars' Press.

Quinn, D. M., Williams, M. K., \& Weisz, B. M. (2015). From discrimination to internalized mental illness stigma: The mediating roles of anticipated discrimination and anticipated stigma. Psychiatric Rehabilitation Journal, 38(2), 
103-108.

Rodriguez, M. C. G. (2016). “The Stories We Tell Each Other”: Using Technology for Resistance and Resilience Through Online Narrative Communities. In Emotions, Technology, and Health (pp. 125-147). Academic Press.

Walls, M. L., Hautala, D., \& Hurley, J. (2014). "Rebuilding our community": Hearing silenced voices on Aboriginal youth suicide. Transcultural Psychiatry, 51(1), 47. 